\title{
LA BASÍLICA DA ASCENSIÓN Y OS FORNOS (ALLARIZ, OURENSE) Y LA CRISTIANIZACIÓN DE LA ARQUITECTURA EN LA ANTIGÜEDAD TARDÍA
}

\author{
REBECA BLANCO-ROTEA ${ }^{(1)}$, SONIA GARCÍA RODRÍGUEZ ${ }^{(2)}$, CRISTINA MATO-FRESÁN $^{(3)}$ \& JORGE \\ SANJURJO-SÁNCHEZ ${ }^{(4)}$
}

Resumen:

\begin{abstract}
Se presenta el estudio arqueológico e histórico del conjunto arquitectónico de la Basílica da Ascensión y $O s$ Fornos (Allariz), un monumento que, a través de sucesivas reformas, ha estado en uso desde la Edad del Hierro hasta la actualidad. Dada la hipótesis que barajamos, creemos que el cambio conceptualmente más importante es la conversión de una sauna vinculada al vecino castro de Armea en un lugar de culto cristiano que conmemora un episodio del martirio de Santa Mariña en el siglo VI. Modificaciones posteriores, de mayor importancia material, perpetúan la dedicación cristiana del edificio.
\end{abstract}

Palabras clave: Arqueología de la Arquitectura, Análisis Estratigráfico de Paramentos, Análisis de Morteros, Edad del Hierro, Antigüedad tardía, Cristianismo primitivo, Galicia, Sauna, Iglesia, Castro de Armea, Santa Mariña.

Abstract:

\begin{abstract}
The Basílica de la Ascensión and Os Fornos (Allariz, Ourense) and the christianization of architecture in Late Antiquity

This paper offers a review of the results of different archaeological projects carried out in the archaeological complex of Basilica de la Ascensión and Os Fornos. This monument has been reused from the Iron Age to the present. Special importance will be given to the transformation of the Iron Age sweat lodge into a christian building linked to the martyrdom of Santa Mariña, in the 6th century. Later transformations will consolidate the christian use of the monument.
\end{abstract}

Keywords: Archaeology of Architecture, Stratigraphic Analysis of Walls, Analysis of Mortars, Iron Age, Late Antiquity, Early Christianism, Galicia, sweat-lodge, Santa Mariña.

\section{INTRODUCCIÓN}

En Galicia se discute la función y fecha de una serie de singulares edificios históricos en cuyo análisis arqueológico se han visto implicados los firmantes de este artículo ${ }^{1}$. Uno de ellos es el conjunto arquitectónico conocido como Basílica ${ }^{2}$ da Ascensión, Os Fornos, o Forno da Santa ${ }^{3}$, sobre el que desarrollamos un programa de estudio interdisciplinar. En este artículo presentaremos este programa de investigación y nuestra hipótesis sobre la relación entre la evolución del conjunto monumental y la difusión de la leyenda de Santa Mariña, pero nos centraremos aquí fundamentalmente en el momento fundacional de este proceso y la arquitectura vinculada al mismo, que acaece, como podremos demostrar, a mediados del siglo VI.

\subsection{Localización y descripción de la Basílica da Ascensión y Os Fornos}

El edificio se ubica en el lugar de Armea, parroquia de Santa Mariña de Augas Santas, ayuntamiento de Allariz (Ourense) (Fig. 1). Se sitúa en una pequeña vaguada, sobre una terraza de origen antrópico, próxima al Castro o "Cibdá de Armea", que, a su vez, está delimitada al oeste por otra terraza (Fig. 2). El conjunto pertenece a la parroquia de Augas Santas, presidida por la iglesia parroquial de Santa Mariña y es uno de los puntos importantes de la red de relaciones que la Santa Patrona tiene con el territorio de la parroquia. El edificio consta de una iglesia sobre el nivel de suelo y una cripta (Fig. 3).

La iglesia (sector 1) presenta una planta absidial, de una sola nave, con cabecera recta. El presbi-

\footnotetext{
(1) Investigadora Contratada del proyecto EMCHAHE (Marie Curie Career Integration Grant; Grant agreement - PCIG12-GA-2012-334068), Laboratorio de Patrimonio, Paleoambiente e Paisaxe, Instituto de Investigacións Tecnolóxicas, Universidade de Santiago de Compostela, Ed. Monte da Condesa, USC, Campus Sur, 15782 Santiago de Compostela. Email: rebeca.blanco.rotea@gmail.com

(2) Independent researcher. C/ Florida 29,3D, Vitoria, 01005. Email: sonia.garcia.ro@gmail.com

(3) Independent researcher. C/ Feliciano Barrera 11D, 4D, Santiago de Compostela, 15706. Email: cristina.mato.fresan@gmail.com

${ }^{(4)}$ Instituto de Xeoloxía "Isidro Parga Pondal", Campus de Elviña, Universidade da Coruña. Email: jsanjurjo@udc.es

${ }^{1}$ San Pedro de Rocas (Ourense) (Blanco-Rotea \& García Rodríguez 2008), Santa Eulalia de Bóveda (Lugo) (Blanco-Rotea et al. 2009b) o la propia Basílica da Ascensión (Allariz) (BLANCO-ROTEA et al. 2009a), entre otros.

2 Aunque el edificio no es una basílica, sino una iglesia, se le denomina así en la bibliografía (LORENZo FERNÁNDEZ 1948; CHAMOSO LAMAS 1955), y hemos mantenido esta denominación. Nos referiremos a ella como basílica cuando empleemos el nombre completo del edificio. La cripta se denomina Os Fornos, o Forno da Santa.

${ }^{3}$ Hornos en castellano.
} 
terio es más estrecho que la nave y el ábside, pues allí se localizan las escaleras de bajada a la cripta Hay una ventana en el muro sur del ábside, rectangular con doble derrame, y una puerta en el muro norte de la nave, de jambas rectas al exterior y con ligero derrame hacia el interior. En el exterior se conservan las basas de unas columnas que enmarcarían esta puerta.

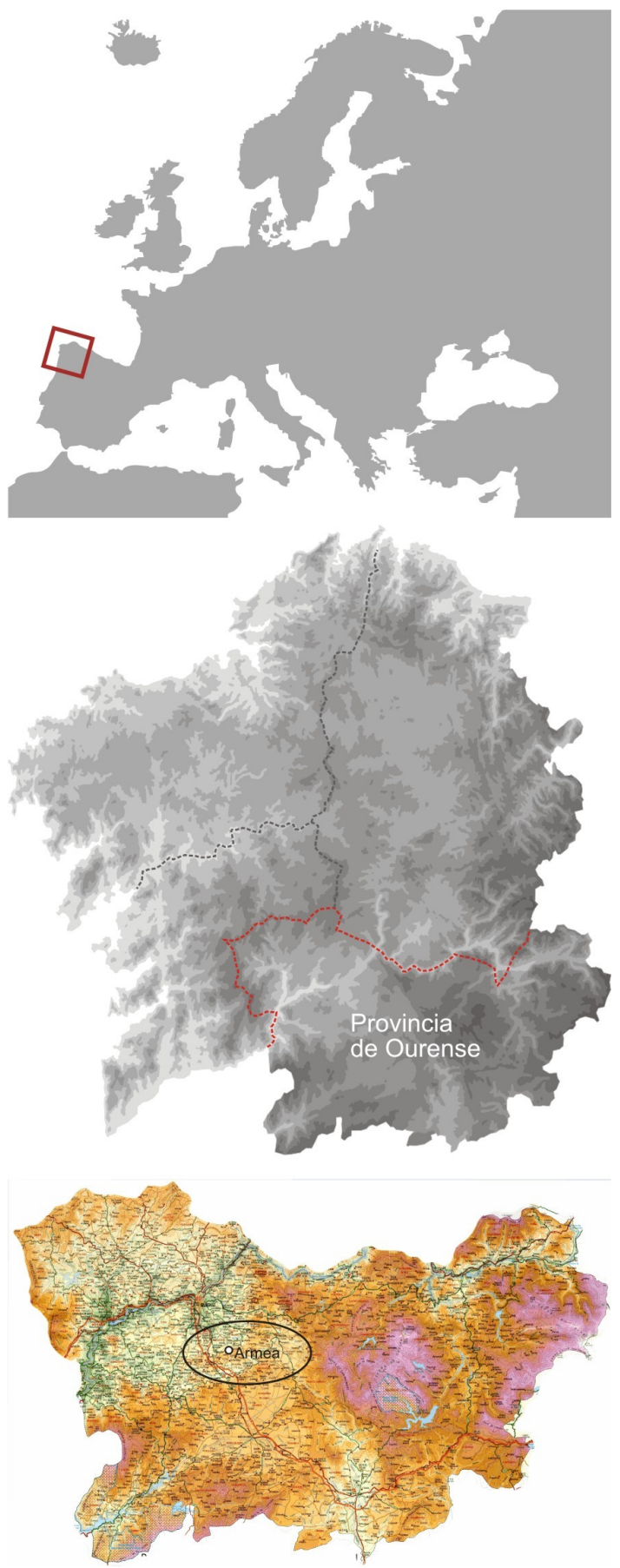

Fig. 1. Mapas de Europa, Galicia y de la provincia de Ourense, en la que se localiza el ayuntamiento de Allariz al que pertenece el lugar de Armea.

Fig. 1. Maps of Europe, Galicia and of the province of Ourense, in which is located the council of Allariz to which belongs the place of Armea.

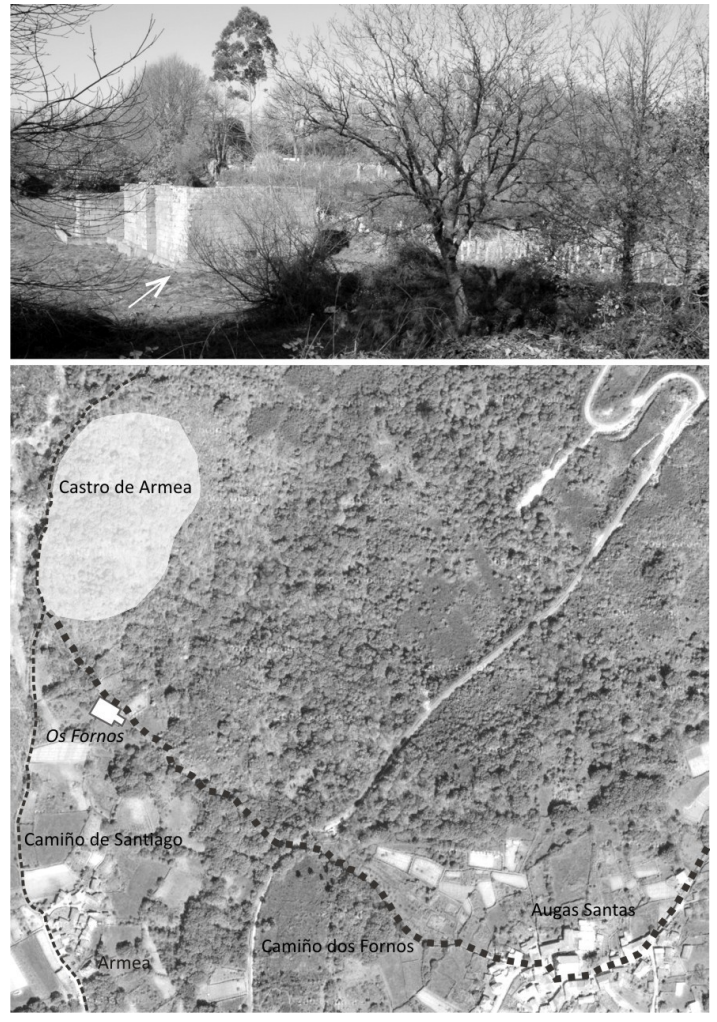

Fig. 2. Arriba, emplazamiento de la Basílica de la Ascensión en el lugar de Armea, a los pies del castro Cibdá de Armea. Abajo, fotografía aérea extraída del SixPac (2008), en la que se han marcado los elementos más relevantes que forman parte del conjunto de Augas Santas-Armea.

Fig. 2. Above, site of the Basilica of Ascension in Armea, at the foot of Cibda of Armea Hillfort (to the left of the image). Down, aerial photograph from the SixPac (2008) showing the most relevant elements of Augas Santas-Armea area.
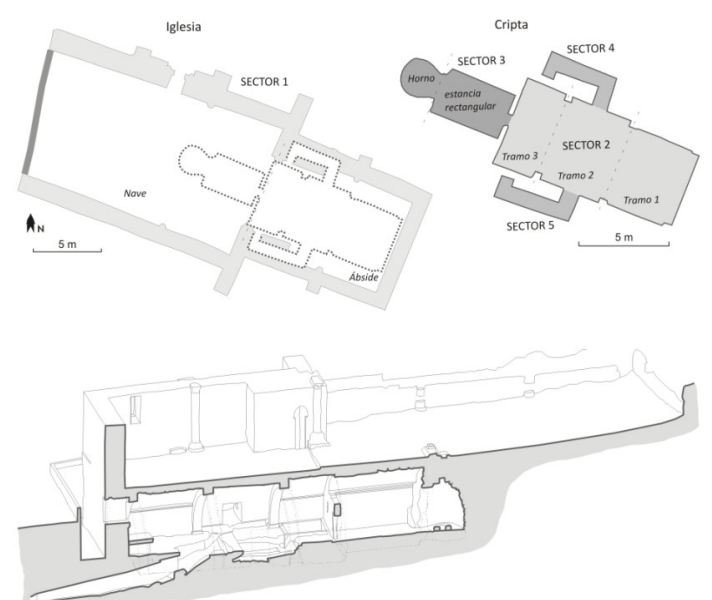

Fig. 3. Arriba, plantas de la basílica y la cripta, en las que se han marcado los sectores de trabajo. Abajo sección longitudinal esteoeste en perspectiva del conjunto, dibujada a partir del escaneado (dibujos de Anxo Rodríguez Paz).

Fig. 3. Above, plants of the basilica and the crypt, showing the studied sectors. Down East-West longitudinal section in perspective, drawn from the scanning (drawings by Anxo Rodríguez Paz). 
Al exterior se localizan varios contrafuertes que coinciden al interior con columnas entregas, en los muros norte y sur del ábside; a la altura del presbiterio se disponen otros dos de mayor desarrollo que los anteriores porque albergan la caja de las escaleras de bajada a la cripta; y a los lados de la puerta de acceso a la nave (Fig. 4).

La cripta se articula en dos estancias (sectores 2 y 3) separadas entre sí por una gran losa de granito (Fig. 6). El sector 2, al este, tiene una planta basilical dividida en tres tramos abovedados de diferente tamaño se-
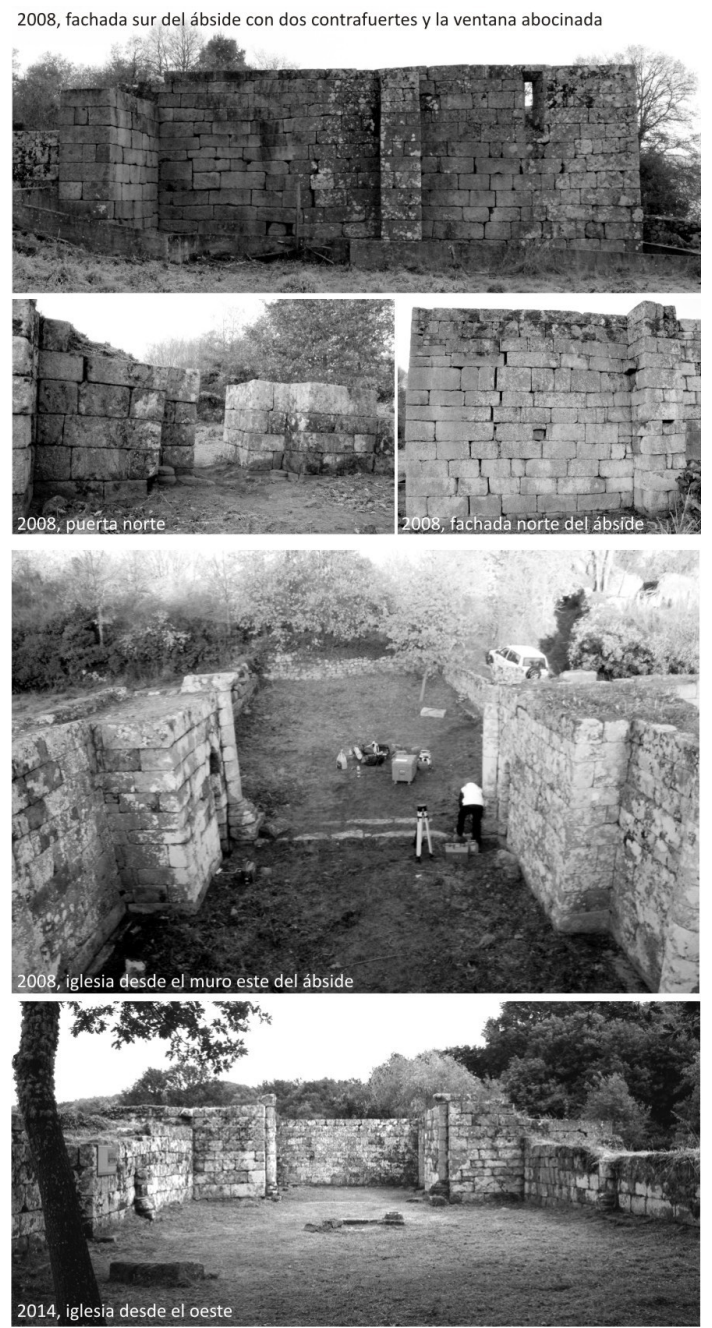

Fig. 4. Distintas vistas de la Basílica da Ascensión y detalle de los paramentos exteriores.

Fig. 4. Different views of the Basilica da Ascensión and detail of the exterior walls. parados por arcos apuntados, siendo el ábside el más oriental (tramo 1). Las paredes de este sector están realizadas en sillería de granito de similares características a la documentada en la iglesia. La entrada de luz a la cripta se produce por una ventana abierta en el muro este (Fig. 5).

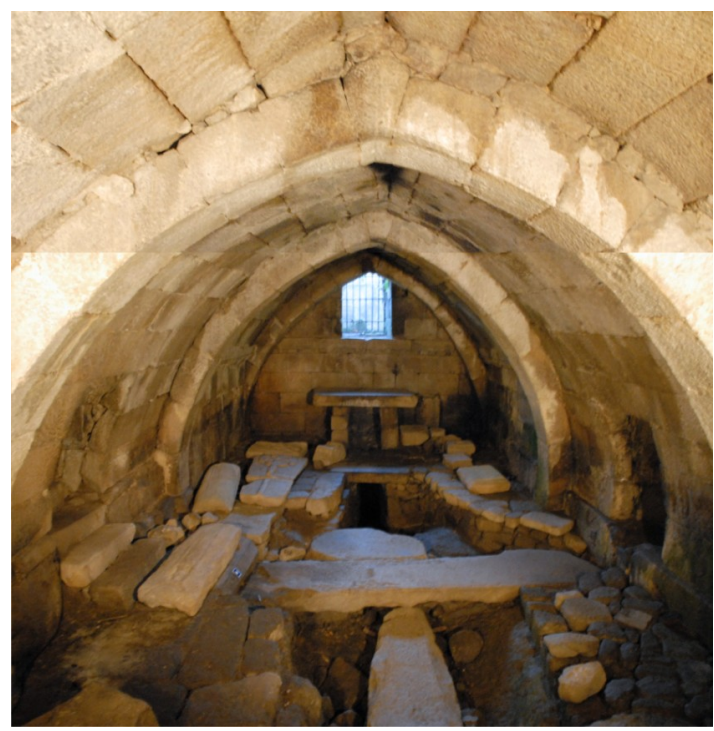

Fig. 5. Sector 2 de la cripta desde el oeste.

Fig. 5. Sector 2 of the crypt from the West.

El suelo del sector 2 está realizado con losas de granito irregulares, aunque está muy alterado con motivo de las intervenciones arqueológicas de mediados del siglo XX, que dejaron al descubierto una canalización que parte del depósito situado en la zona suroeste y pasa por debajo del muro este. La ausencia de suelo hace que la cripta sea de difícil tránsito. Apoyadas en las paredes hay laudas sepulcrales que estaban reutilizadas en el enlosado delante de la entrada al sector 3 (LORENZO FERNÁNDEZ 1948: Lam. III).

En el extremo occidental del sector 2 se localiza una gran losa de granito emparentada con las pedras formosas propias de las saunas de la Edad del Hierro del Norte de Portugal ${ }^{4}$ (LORENZO FERNÁNDEZ 1948: 176; CHAMOSO LAMAS 1955: 61-64) que da acceso a una estancia de planta rectangular (Figs. 3 y 6). Tiene un vano descentrado a cuyos lados se localizan dos relieves identificados como dragones o bichas (CALVO 1913: 348; LORENZO FERNÁNDEZ 1948: 176; FARIÑA BUSTO 2002: 54), pero en realidad de difícil interpretación.

El sector 3 está formado por dos estancias, una de planta rectangular y, otra de planta circular en el

\footnotetext{
${ }^{4}$ Tipo de edificio detectado en una veintena de castros en dos grupos. Uno meridional entre el río Miño y el Duero, otro septentrional en el valle del Navia en sentido amplio y la costa Cantábrica. Su denominación ha fluctuado enfatizándose la interpretación (baños, hornos, crematorios...) o algún elemento constructivo (pedra Formosa, monumento con forno...). Su función como sauna se admite en la actualidad y las variantes formales invitan a prescindir de la terminología que se apoya en ellas (GARCÍA QuiNTELA \& SANTOS-ESTÉVEZ 2015).

${ }^{5}$ Lo explica el obispo Muñoz de la Cueva: "En este más profundo pavimento, inundado de agua la mayor parte del año, se ven con la luz escasa de unas claraboyas, dos hornos ennegrecidos de humo, y son donde Santa Marina padeció el martirio del fuego. Prueba es también de la firmeza de esta fábrica el que no la haya derrotado la avaricia, que buscando tesoros, ha movido, y desencajado muchas de sus piedras. En lo alto de esta bóveda está el pequeño agujero por donde, como ya escribí, tiene la tradición, que el Apóstol San Pedro sacó a Marina del homo" [MUÑOZ DE LA CUEVA 1726 (2008): 65]. Ver sobre las relaciones de la leyenda con los restos arqueológicos del lugar GARCía QUINTELA 2014a y 2014b.
} 
extremo oeste (forno) (Fig. 3). La rectangular está delimitada al este por la pedra formosa, al oeste por el forno y los muros norte y sur son de sillería. Está cubierta por una bóveda de sillería generada por un arco de medio punto (Fig. 6). El forno es un espacio de reducidas dimensiones de planta circular abovedada rematada por una losa con un agujero circular que la tradición vincula con la leyenda de Santa Mariña (Fig. 7). El suelo presenta un enlosado de grades piezas de granito.

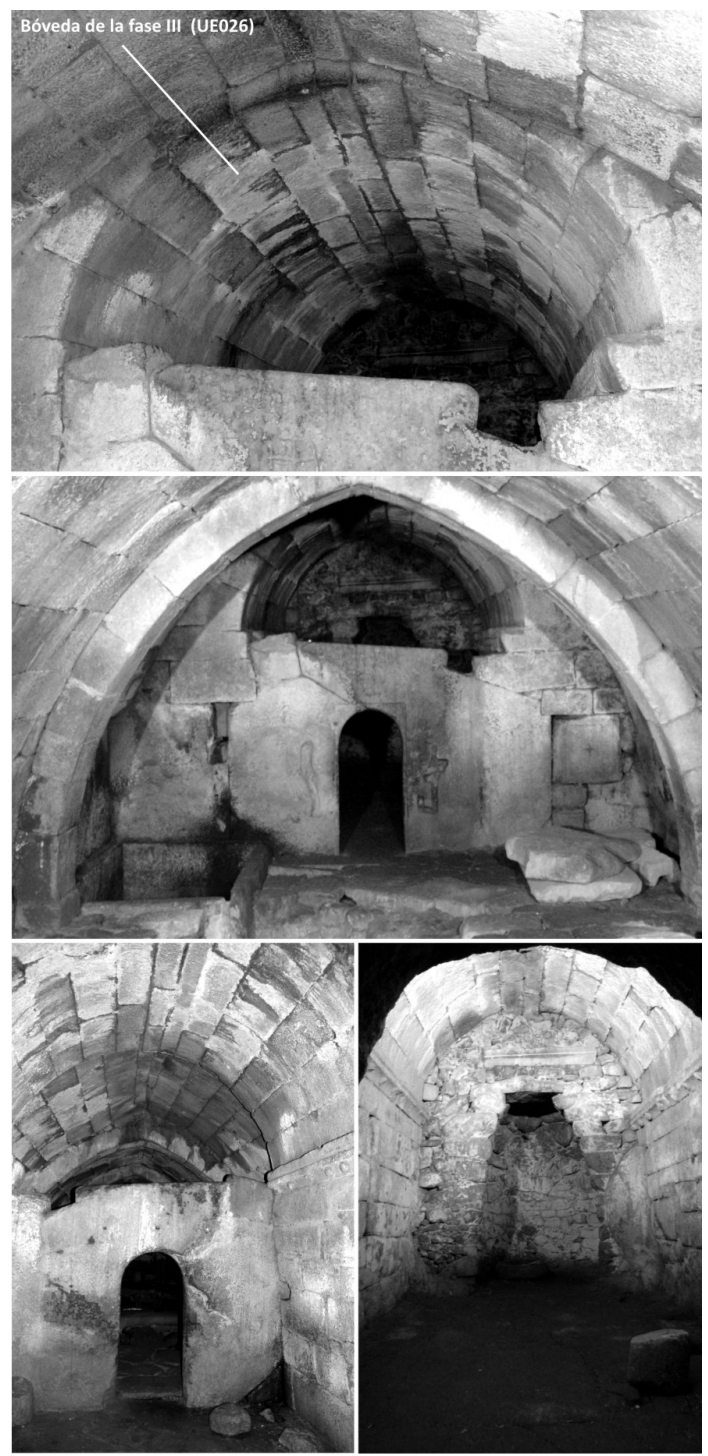

Fig. 6. Vistas de la cripta. Arriba, detalle de la bóveda de sillería correspondiente a la fase III que cubre el sector 3. Centro, lado este de la pedra formosa que da acceso al sector 3, a la izquierda el depósito de la Fase II. Abajo, izquierda, lado oeste de la pedra formosa; derecha, el sector 3 con la estancia de la Fase II y, al fondo, el horno de la Fase I.

Fig. 6. Views of the crypt. Above, detail of the stone vault corresponding to the phase III that covers the sector 3. Center, east side of the pedra formosa which gives access to sector 3 , to the left the water reservoir of the Phase II. Down, left, west side of the pedra formosa; right, sector 3 with the stay of the Phase II and, in the background, the oven of the Phase I.
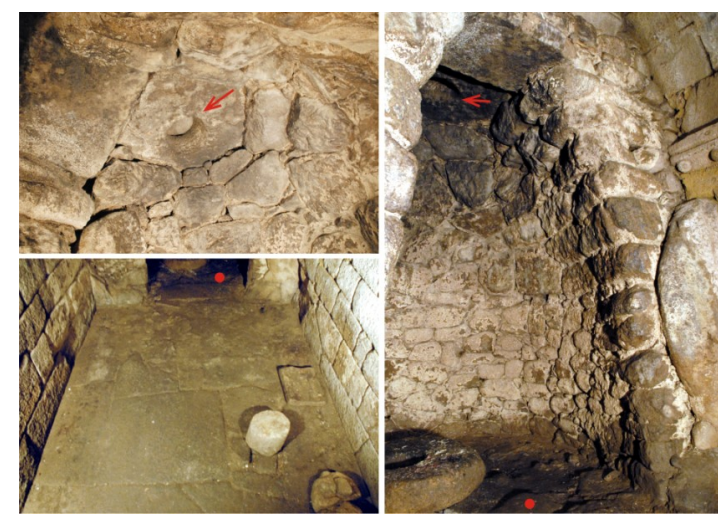

Fig. 7. Elementos identificados dentro de la fase I. Se puede ver la piedra que remata el forno, el acceso a este y el suelo de la estancia anterior.

Fig. 7. Elements identified in phase I. It is possible to see the stone that covers the "forno", the access to this one and the soil of the previous area.

\subsection{Planteamientos del estudio de un edificio complejo}

Cuando iniciamos los trabajos fue necesario tener en cuenta el espesor temporal de un edificio que se remontaba a la Edad del Hierro, por la presencia en la cripta de los posibles restos de una sauna de ese periodo, y su vinculación con la leyenda del martirio de Santa Mariña. El estudio de esta doble dimensión se ha desarrollado a lo largo de tres fases.

La primera fase (2007) se encaminaba a la documentación y análisis de su arquitectura, para lo cual se hizo la documentación tridimensional del edificio mediante Láser Escáner 3D (MAÑANA-BORRAZÁs et al. 2008) y el análisis estratigráfico de paramentos (BLANCO-RoTEA et al. 2009a) (Tabla 1, Figs. 8, 9, 10, 11).

Sin embargo la cronología absoluta de la secuencia estratigráfica presentaba problemas. Las fases medievales se podían datar fácilmente gracias a la presencia de aparejos o elementos formales y decorativos (los arcos apuntados, la moldura de bolas, la decoración de los capiteles y el tímpano, las basas) bien conocidos para esa época. Pero esto no era posible para las fases más antiguas debido a la ausencia de documentación histórica, de elementos decorativos y, sobre todo, de estudios arqueológicos sistemáticos en Galicia sobre arquitectura tardoantigua y altomedieval que posibilitasen el recurso a una tipología bien establecida de técnicas constructivas. Por ello implementamos en una segunda fase un programa de datación absoluta del edificio y la terraza adyacente que probablemente se habría alterado en paralelo con la transformación del edificio.

Esta fase constaba de dos actuaciones. En el año 2012 se realizó un programa de caracterización y datación de muestras de los morteros conservados en las diferentes fases de la cripta. La datación de los materiales constructivos se realizó por Lu- 
Tabla 1. Listado de Actividades (Act) y Unidades Estratigráficas (UE) diferenciadas mediante la lectura estratigráfica de paramentos.

Table 1. List of activities (Act) and stratigraphic units (EU) differentiated by stratigraphic analysis of walls

\begin{tabular}{|c|c|c|c|c|c|c|c|}
\hline$F^{1}$ & Act & $\begin{array}{l}\text { Nombre de } \\
\text { la Act }\end{array}$ & Sect & $\mathbf{U E}^{2}$ & Nombre de la UE & Ant a Act & Post a Act \\
\hline \multirow{11}{*}{ I } & \multirow{5}{*}{101} & \multirow{5}{*}{$\begin{array}{l}\text { Construcción } \\
\text { del primer } \\
\text { canal }\end{array}$} & 02 & UE037 & Corte en el sustrato rocoso para canalización. & \multirow{5}{*}{104,110} & \\
\hline & & & 02 & UE038 & Muro de mampostería en el extremo este del canal. & & \\
\hline & & & 02 & UE041 & Losa de gran tamaño sobre canal. & & \\
\hline & & & 02 & UE046 & Pieza de granito bajo el altar con un agujero en el centro. & & \\
\hline & & & 02 & UE074 & Corte en sustrato rocoso para canalización. & & \\
\hline & \multirow{6}{*}{102} & \multirow{6}{*}{$\begin{array}{l}\text { Construcción } \\
\text { del forno }\end{array}$} & 03 & UE051? & Suelo de la estancia anterior al forno. & \multirow{6}{*}{$\begin{array}{l}104,105 \\
117\end{array}$} & \\
\hline & & & 03 & UE053 & Losa de granito de forma en vertical delante del forno. & & \\
\hline & & & 03 & UE054 & Restos losa de granito dispuesta en vertical delante del forno. & & \\
\hline & & & 03 & UE057 & Muro de "horno". & & \\
\hline & & & 03 & UE059 & Losa de granito con agujero central en parte superior del forno. & & \\
\hline & & & 03 & UE061? & Suelo del forno. & & \\
\hline \multirow{3}{*}{ I/II } & \multirow{3}{*}{103} & \multirow{3}{*}{$\begin{array}{l}\text { Construcción } \\
\text { de parte baja } \\
\text { del muro } \\
\text { norte de la } \\
\text { cripta }\end{array}$} & 02 & UE012 & $\begin{array}{l}\text { Muro de sillería sobre zócalo, en parte baja del muro norte de la } \\
\text { cripta. }\end{array}$ & \multirow{3}{*}{$\begin{array}{l}104,106 \\
111\end{array}$} & \\
\hline & & & 02 & UE013 & $\begin{array}{l}\text { Muro de sillería sobre sustrato rocoso trabajado, en la parte baja del } \\
\text { muro norte de la cripta. }\end{array}$ & & \\
\hline & & & 02 & UE067 & Pared en parte baja del muro norte del tercer tramo de la cripta. & & \\
\hline \multirow{14}{*}{ II } & \multirow{14}{*}{104} & \multirow{14}{*}{$\begin{array}{l}\text { Construc- } \\
\text { ción/reforma } \\
\text { de la estancia } \\
\text { delante del } \\
\text { forno, segun- } \\
\text { da canaliza- } \\
\text { ción y de- } \\
\text { pósito de } \\
\text { agua }\end{array}$} & 02 & UE022 & Losas de granito en paredes sur y oeste del tercer tramo de la cripta & \multirow{14}{*}{$\begin{array}{l}105,106, \\
110,111, \\
113\end{array}$} & \multirow{14}{*}{$\begin{array}{l}101,102 \\
103\end{array}$} \\
\hline & & & 02 & UE023 & Losa de granito decorada, cierre este de la estancia anterior al forno. & & \\
\hline & & & 02 & UE025 & Canalización que sale de la pared oeste del tercer tramo de la cripta. & & \\
\hline & & & 02 & UE027 & $\begin{array}{l}\text { Extremo norte de la pared oeste del tercer tramo de la cripta, forma- } \\
\text { do por la roca trabajada, sillares reutilizados y mampuestos. }\end{array}$ & & \\
\hline & & & 02 & UE033 & Rebaje rectangular alrededor del vano de la losa decorada (UE023). & & \\
\hline & & & 02 & UE034 & Cuatro agujeros a los lados del vano de la losa decorada. & & \\
\hline & & & 02 & UE035 & Restos de hierro que rellena uno de los agujeros de la UE034. & & \\
\hline & & & $\begin{array}{c}02 / 0 \\
3\end{array}$ & UE036 & Apertura de un vano en losa decorada. & & \\
\hline & & & 02 & UE044? & Depósito de agua rectangular, con paredes de losas de granito. & & \\
\hline & & & 03 & UE049 & Muro de sillería sur de la estancia anterior al forno. & & \\
\hline & & & 03 & UE050 & Muro de sillería norte de la estancia anterior al forno. & & \\
\hline & & & 03 & UE055 & Interfaz de corte de la losa UE 054. & & \\
\hline & & & 03 & UE056 & Relleno con mampostería de la rotura en UE054. & & \\
\hline & & & 02 & UE071 & Corte realizado sobre el corte UE037 para segundo canal. & & \\
\hline \multirow{6}{*}{ III } & \multirow{6}{*}{105} & \multirow{6}{*}{$\begin{array}{l}\text { Construcción } \\
\text { de la bóveda } \\
\text { que cubre la } \\
\text { estancia } \\
\text { anterior al } \\
\text { forno }\end{array}$} & 02 & UE026 & $\begin{array}{l}\text { Bóveda de cañón de medio punto de sillería en estancia anterior al } \\
\text { forno. }\end{array}$ & \multirow{6}{*}{106} & \multirow{6}{*}{102,104} \\
\hline & & & 03 & UE048 & Molduras de bolas en la bóveda UE026. & & \\
\hline & & & 03 & UE058 & Recrecido del horno en mampostería con material reutilizado. & & \\
\hline & & & 02 & UE062 & Corte en L en el lado norte de la losa decorada. & & \\
\hline & & & 02 & UE063 & Corte irregular en el lado sur de la losa decorada. & & \\
\hline & & & 02 & UE065 & $\begin{array}{l}\text { Corte rectangular para disponer sillar de la UE026 sobre losa de la } \\
\text { UE022. }\end{array}$ & & \\
\hline
\end{tabular}




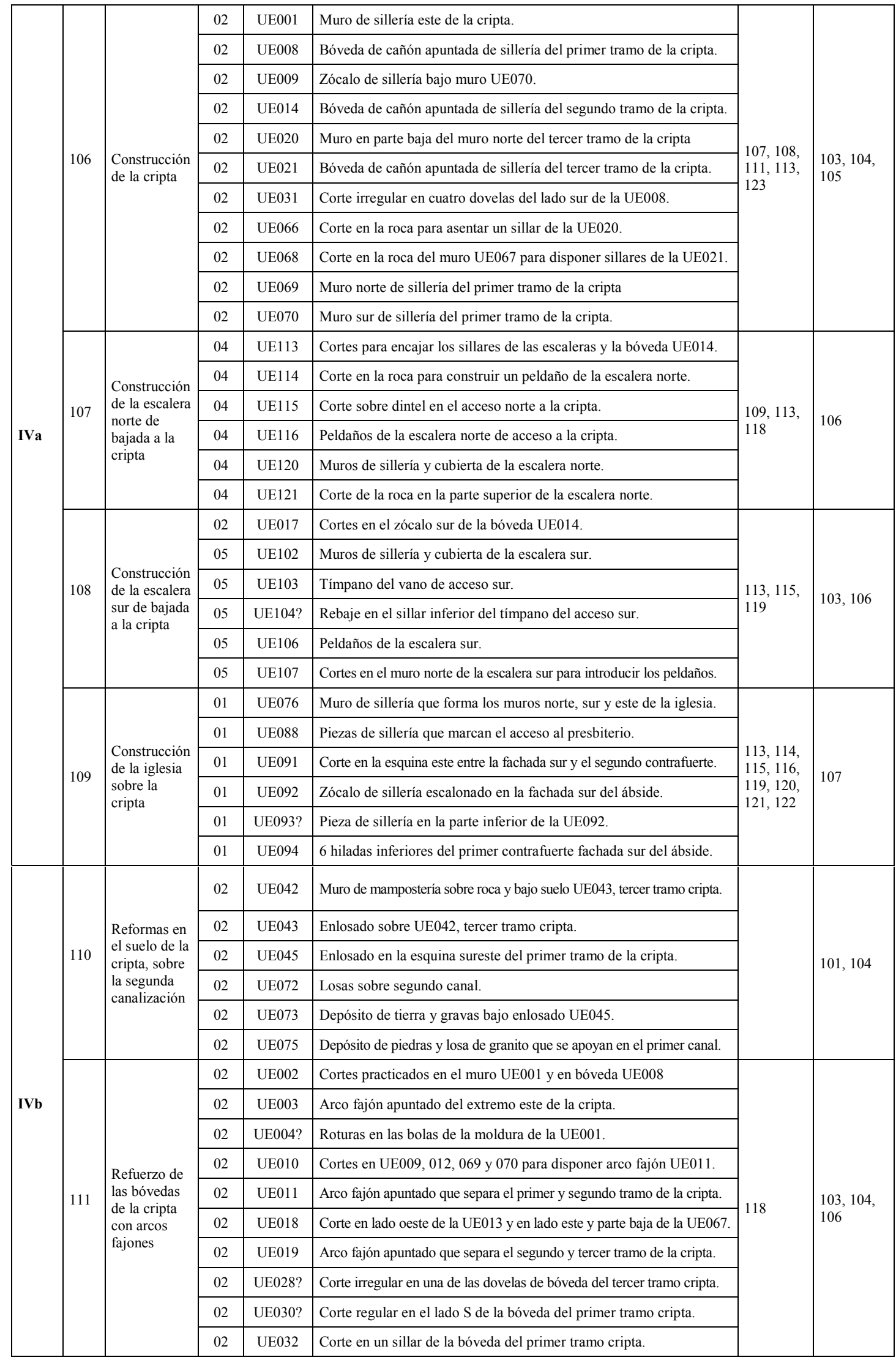




\begin{tabular}{|c|c|c|c|c|c|c|c|}
\hline \multirow{18}{*}{$\mathbf{V}$} & 112 & $\begin{array}{l}\text { Altar este de } \\
\text { la cripta }\end{array}$ & 02 & UE007 & Mesa de altar. & & 110 \\
\hline & \multirow{8}{*}{113} & \multirow{8}{*}{$\begin{array}{l}\text { Cortes y } \\
\text { reparaciones } \\
\text { con mortero }\end{array}$} & 02 & UE029 & Mortero en juntas y roturas de la bóveda del tercer tramo cripta. & & \multirow{8}{*}{$\begin{array}{l}104,105, \\
106,107, \\
108,109\end{array}$} \\
\hline & & & 03 & UE052 & Reparaciones con mortero de grietas y roturas de la losa UE023. & & \\
\hline & & & 01 & UE082? & $\begin{array}{l}\text { Restos de mortero rosáceo sobre sillar del segundo contrafuerte } \\
\text { desde el este de la fachada norte del ábside. }\end{array}$ & & \\
\hline & & & 01 & UE095? & Restos de mortero de cal en la fachada sur de la iglesia. & & \\
\hline & & & 05 & UE111 & Corte en parte superior del muro sur de la escalera sur. & & \\
\hline & & & 04 & UE112? & Rebaje en tres sillares parte inferior muros sur y oeste de escalera sur. & & \\
\hline & & & 04 & UE119 & Mortero de junta en varias zonas del muro norte de escalera norte. & & \\
\hline & & & 05 & UE122 & Mortero en varias juntas del muro sur de escalera sur. & & \\
\hline & \multirow{2}{*}{114} & \multirow{2}{*}{$\begin{array}{l}\text { Colocación } \\
\text { de reja en } \\
\text { ventana este } \\
\text { de la cripta }\end{array}$} & 02 & UE005 & Agujeros para reja en la ventana de la UE001. & \multirow[b]{2}{*}{119} & \multirow[b]{2}{*}{109} \\
\hline & & & 02 & UE006 & Reja de barrotes de sección cuadrangular de la ventana de la cripta. & & \\
\hline & \multirow{6}{*}{115} & \multirow{6}{*}{$\begin{array}{l}\text { Reformas en } \\
\text { las escaleras } \\
\text { de bajada a } \\
\text { la cripta }\end{array}$} & 02 & UE015 & $\begin{array}{l}\text { Cortes practicados en las UE012, UE013 y UE014 para disponer los } \\
\text { tres últimos peldaños de la escalera norte de bajada a la cripta. }\end{array}$ & \multirow{6}{*}{119} & \multirow{6}{*}{108,109} \\
\hline & & & 02 & UE016 & Tres últimos peldaños de la escalera norte. & & \\
\hline & & & 01 & UE083 & Mortero en el umbral del ventanuco del muro norte, escalera norte. & & \\
\hline & & & 05 & UE108 & Corte en parte inferior de jambas y umbral del acceso sur. & & \\
\hline & & & 05 & UE110 & Dos peldaños en el primer tramo de la escalera sur. & & \\
\hline & & & 04 & UE118 & Apertura de ventanuco en el muro norte, escalera norte. & & \\
\hline & 116 & $\begin{array}{l}\text { Muro oeste } \\
\text { iglesia }\end{array}$ & 01 & UE087 & $\begin{array}{l}\text { Muro de mampostería que cierra por el oeste del espacio de la nave } \\
\text { de la iglesia. }\end{array}$ & & 109 \\
\hline \multirow{3}{*}{ VIa } & 117 & $\begin{array}{l}\text { Cierre del } \\
\text { agujero del } \\
\text { forno }\end{array}$ & 03 & UE060 & Pieza de granito que tapa el agujero de la UE059. & & 102 \\
\hline & \multirow{2}{*}{118} & \multirow{2}{*}{$\begin{array}{l}\text { Reforma en } \\
\text { el suelo de la } \\
\text { cripta }\end{array}$} & 02 & UE039 & Suelo de losas de granito irregulares sobre el muro UE038. & & \multirow{2}{*}{$\begin{array}{l}106,107, \\
111\end{array}$} \\
\hline & & & 02 & UE040 & Enlosado de prácticamente la mitad norte de la cripta. & & \\
\hline \multirow{5}{*}{ VI } & \multirow{5}{*}{119} & \multirow{5}{*}{$\begin{array}{l}\text { Reparaciones } \\
\text { de cortes y } \\
\text { agujeros con } \\
\text { mortero de } \\
\text { cemento }\end{array}$} & 02 & UE064 & $\begin{array}{l}\text { Reparaciones con cemento de grietas y juntas en lado norte del } \\
\text { depósito UE044. }\end{array}$ & & \multirow{5}{*}{$\begin{array}{l}104,108, \\
109,114, \\
115\end{array}$} \\
\hline & & & 01 & UE077 & Mortero de cemento que rellena roturas en la ventana de la cripta. & & \\
\hline & & & 05 & UE105 & Mortero de cemento en varias juntas del muro este, escalera sur. & & \\
\hline & & & 05 & UE109 & Mortero de cemento en umbral de puerta sur de acceso a la cripta. & & \\
\hline & & & 04 & UE117 & Mortero de cemento bajo el ventanuco de la escalera norte. & & \\
\hline VIa & 120 & $\begin{array}{l}\text { Reconstruc- } \\
\text { ción en la } \\
\text { iglesia }\end{array}$ & 01 & UE086 & $\begin{array}{l}\text { Reconstrucción en mampostería de la fachada sur de la nave de la } \\
\text { iglesia. }\end{array}$ & & 109 \\
\hline \multirow[b]{2}{*}{ VIb } & \multirow[b]{2}{*}{121} & \multirow{2}{*}{$\begin{array}{l}\text { Construcción } \\
\text { de zanja en } \\
\text { fachadas este } \\
\text { y sur de } \\
\text { iglesia }\end{array}$} & 01 & UE078 & Muro de hormigón que se adosa a las fachadas sur y este de la iglesia. & & \multirow[b]{2}{*}{101,109} \\
\hline & & & 01 & UE090 & $\begin{array}{l}\text { Sillar de granito en parte inferior de segundo contrafuerte este de la } \\
\text { fachada sur. }\end{array}$ & & \\
\hline \multirow{5}{*}{ VI } & \multirow{5}{*}{122} & \multirow{5}{*}{$\begin{array}{l}\text { Grietas de } \\
\text { asiento en } \\
\text { los muros } \\
\text { exteriores del } \\
\text { conjunto }\end{array}$} & 01 & UE079 & Grieta en el extremo este de la fachada norte del ábside. & & \multirow{5}{*}{101,109} \\
\hline & & & 01 & UE080 & Grieta en la fachada norte del ábside, segundo tramo, zona media-baja. & & \\
\hline & & & 01 & UE081 & Grieta en la fachada norte del ábside, segundo tramo, zona alta. & & \\
\hline & & & 01 & UE084 & $\begin{array}{l}\text { Grieta en el muro norte de tercer contrafuerte por el este de fachada } \\
\text { norte iglesia. }\end{array}$ & & \\
\hline & & & 01 & UE085 & Grieta en el segundo tramo de la fachada sur del ábside. & & \\
\hline V-VI & 123 & $\begin{array}{l}\text { Cortes en la } \\
\text { bóveda de a } \\
\text { cripta }\end{array}$ & 02 & UE100 & Rebaje rectangular en el sillar de la bóveda, segundo tramo de la cripta. & & 106 \\
\hline
\end{tabular}

Leyenda: F: Fase; Act: Actividad; Sect: Sector; UE: Unidad Estratigráfica; Ant a Act: Anterior a Actividad; Post a Act: Posterior a Actividad. Durante los procesos de simplificación, correlación y periodización de la lectura estratigráfica, se han eliminado las UE024, UE047, UE089, UE096, UE097, UE098 y UE099, por ello no figuran en el listado 

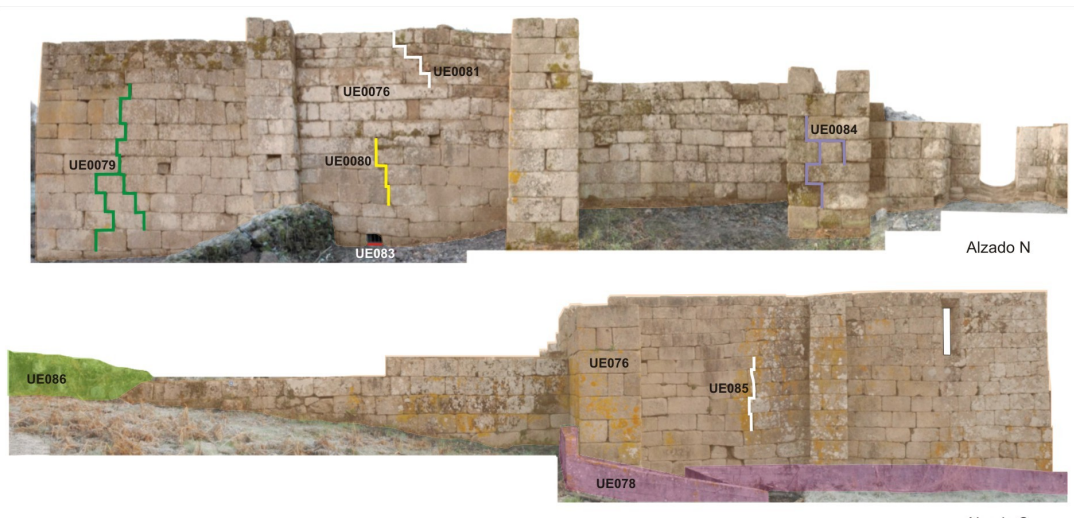

Fig. 8. Lectura de paramentos de los muros norte y sur de la Basílica da Ascensión.

Fig. 8. Stratigraphic analysis of the North and South walls of the Basilica da Ascensión.

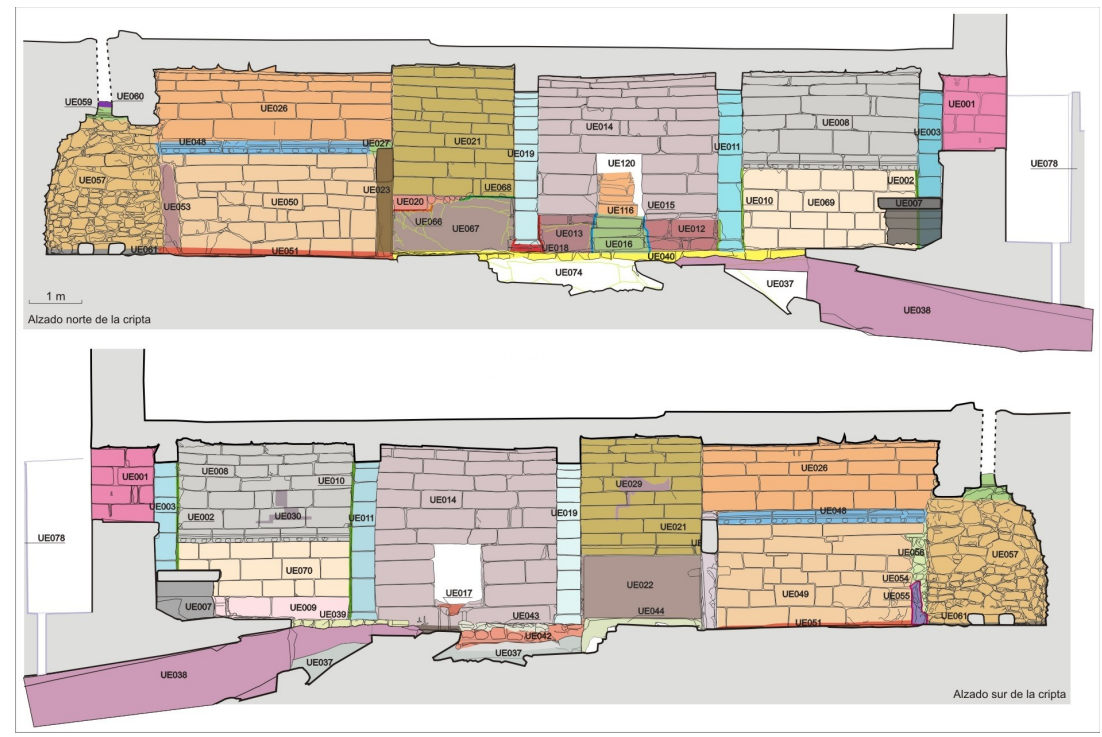

Fig. 9. Lectura de paramentos de los muros norte y sur de la cripta.

Fig. 9. Stratigraphic analysis of the North and South walls of the crypt.

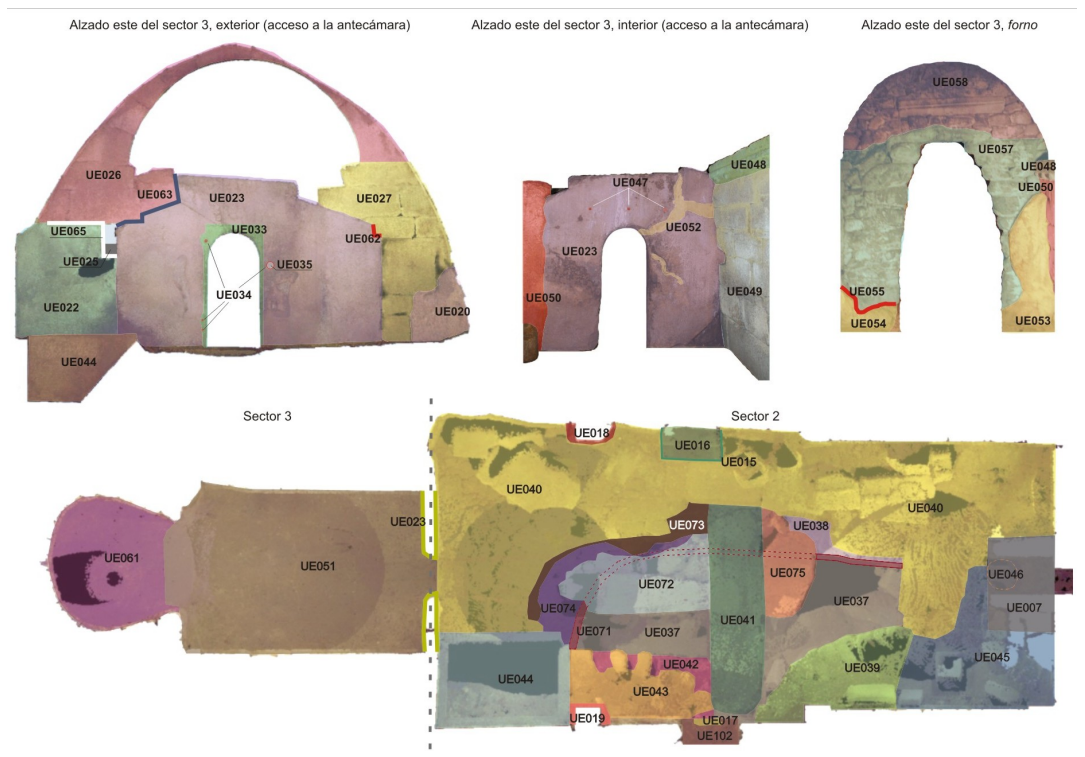

Fig. 10. Lectura de paramentos de varios muros del sector 3 y de la planta de la cripta. Fig. 10. Stratigraphic analysis of several walls of the sector 3 and the plant of the crypt. 


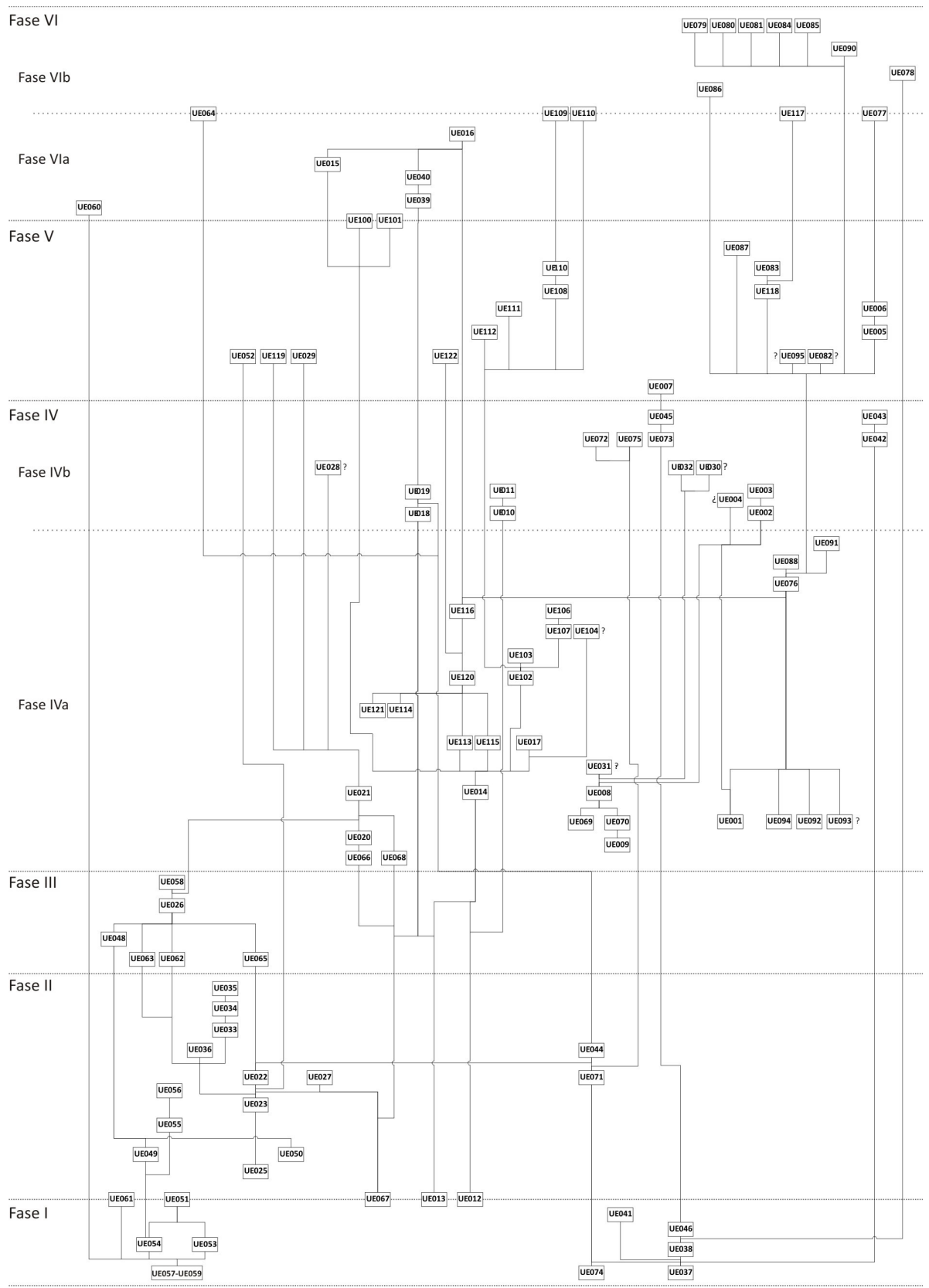

Fig. 11. Diagrama estratigráfico de UE

Fig. 11. Stratigraphic Diagram of SU.

miniscencia Ópticamente Estimulada (OSL). La elección de la luminiscencia como herramienta para la datación se hizo en base a la composición de los morteros. Al no tratarse de morteros de cal, podría haberse usado como método de datación el radiocarbono (QUIRÓs CASTILLO et al. 2011), siempre que hubiera materia orgánica, pero esto genera problemas (SANJURJo SÁNCHEZ 2012; PESCE \& BALL 2012) ya que el resultado indicaría la edad del material orgánico del suelo usado en el mortero, y no de la construcción de los paramentos (SANJURJO SÁNCHEZ 2012) que era nuestro objetivo. Para abordarlo la alternativa era la luminiscen- cia (GoEdicke 2011; SANJURJO SÁNCHEZ 2012), técnica también testada en morteros de arcilla con resultados satisfactorios (FEATHERS et al. 2008). Este método permite datar la construcción del paramento, si se data el mortero del interior o de la junta de los muros, o de la aplicación posterior de un mortero en un muro, bien en las juntas o como revestimiento, es decir, una fecha postquem al muro original.

Por otra parte, se realizaron análisis mineralógicos y químicos del material datado para caracterizar los originales y las reposiciones posteriores. Se hizo Difracción de Rayos X (DRX), para 
conocer su composición mineral, y análisis por Activación de Neutrones (AAN) para conocer la composición elemental. Los resultados de ambos trabajos se publicarán próximamente y nos limitaremos a exponer los datos pertinentes para comprender la estratigrafía y cronología del edificio.

Con todo carecíamos de respuestas sobre la funcionalidad original del Forno, como parte de una sauna de la Edad del Hierro (GARCÍA QUNTELA \& SANTOS-ESTÉVEZ 2015) y, sucesivamente, la funcionalidad del espacio reformado delante de este forno. Antes de plantear una intervención de mayor envergadura decidimos hacer en 2013 una valoración de la estratigrafía de las terrazas mediante sondeos geotécnicos para recoger muestras de suelos. Nuestra intención era evaluar las transformaciones sufridas en el entorno tanto como consecuencia de la construcción del conjunto como, posteriormente, por la utilización de este entorno en actividades rituales o mediante su explotación agraria. Los resultados, todavía preliminares y que se publicarán oportunamente, remiten a época pleno medieval y posterior; algo interesante para fijar la cronología del edificio en esos períodos, pero lejos del foco del presente artículo, las primeras fases cristianas del edificio.

La tercera fase de estudio, en curso, se extiende al conjunto de las iglesias altomedievales del centro de la provincia de Ourense. Se documentará su secuencia constructiva mediante una lectura estratigráfica de registro rápido, las técnicas empleadas y la tipología de elementos tecno-formales (aparejos, de plantas o de elementos decorativos). Seguidamente se procederá a un estudio comparativo de los aparejos y, en caso de conservarse morteros, a la toma de muestras para su caracterización y datación. Esto permitirá identificar y caracterizar las técnicas constructivas de fechas cercanas a las de Augas Santas y comprender las transformaciones del primer edificio de la Ascensión en un contexto más amplio.

\section{ANÁLISIS HISTÓRICO-DOCUMENTAL}

La mayoría de los estudios sobre el edificio se detienen en el origen de la cripta y su transformación a lo largo del tiempo. Los estudios se han centrado en la vinculación de la cripta con el Castro de Armea y su identificación como una sauna de la Edad del Hierro y, por otro lado, en la implantación de la leyenda del martirio de Santa Mariña en este territorio.

\subsection{El conjunto arquitectónico formado por la iglesia y la cripta}

En 1913 Feliciano Calvo publica una serie de artículos donde da a conocer los lugares que se veneran en Augas Santas ${ }^{6}$. Calvo defiende la idea de que estos lugares se apropian de otros anteriores de uso céltico-romano que habrían pasado por el tamiz del cristianismo a partir del siglo VI. Cuando aborda el estudio del forno insiste en su antigüedad y lo vincula a un lugar de sacrificios. Considera que la Pedra Formosa se habría trasladado a posteriori durante la cristianización del lugar.

Xaquín Lorenzo Fernández tras excavar la cripta publica en 1948 un artículo dedicado al forno, donde relaciona la construcción con la fornalha castrexa de Briteiros (Portugal), cuya estructura tiene un gran paralelismo con la de la cripta, y la compara con edificaciones de los castros de Coaña y Pendia en Asturias (GARCÍA Y BELlido 1940; 1942). Interpreta estas estructuras como hornos crematorios de uso funerario y considera el Forno da Santa de origen prerromano, reconvertido en ninfeo romano y en baptisterio cristiano, momento en el que las aguas adquieren el carácter santo en relación con la leyenda de Santa Mariña.

Francisco Conde-Valvís presenta en 1955 un trabajo sobre el monumento y en 1959 otro sobre sus excavaciones en el Castro de Armea. Considera que el forno es un hipocaustum romano, sostiene que estaría comunicado con las estancias superiores interpretadas como un palacio o como baños público. Augas Santas sería pues un ejemplo de arquitectura termal de origen romano. Su investigación se centró también en el uso y funcionalidad de la piscina ${ }^{7}$ y su sistema de alimentación. Para el autor estaría abastecida por un pequeño canal que nace en la cercana Fonte do Cal y recorre $75 \mathrm{~m}$ antes de alcanzar el edificio. El tramo final sería de losas hincadas a modo de paredes; atravesaría el muro por debajo de las escaleras hasta desembocar en la "piscina", por un caño que en su tramo final gira $90^{\circ}$ en dirección este. El canal de desagüe partiría por debajo del muro este de la cripta y recorre $36 \mathrm{~m}$ hasta desembocar en el regato de Armea ${ }^{8}$.

En 1955 Manuel Chamoso Lamas publica un trabajo centrado la cripta y forno y ofrece un dato novedoso en torno al sistema de alimentación de la piscina pues revela la existencia de un canal a menor cota que el caño que la abastecería habitualmente. Destaca la importancia del agua en la construcción dado el cuidado desplegado para su correcta canalización. Finalmente desecha la interpretación como crematorio que le atribuyó Lorenzo y sugiere su origen castreño y su función ritual.

Los trabajos posteriores se centran en la iglesia parroquial y del palacio arzobispal de la aldea de Augas Santas, mientras que se aproximan casi anecdóticamente a la iglesia y cripta de Armea (BANDE RODRÍGUEZ \& ARMADA BANDE 2002;

${ }^{6}$ Prácticamente todos los autores se refieren a la Basílica de la Ascensión y Os Fornos como Augas Santas, topónimo que ha adquirido un mayor protagonismo por la construcción en plena Edad Media de la iglesia parroquial en el lugar donde habían manado tres fuentes cuando se produjo el martirio de Santa Mariña. Sin embargo, la cripta y la iglesia que estudiamos se localizan en Armea, como hemos visto. Respetaremos en esta revisión la referencia que hacen los autores a Augas Santas.

${ }^{7} \mathrm{Se}$ refiere al depósito de agua.

${ }^{8}$ Conocido localmente como O Regueiriño. 
FARIÑA BUSTO 2002). Por otro lado se asume que la Basílica da Ascensión, construida sobre la cripta, es un edificio inconcluso, como sostiene Muñoz de la Cueva (1726: 65). Los autores consultados fechan la iglesia en el siglo XIII (LORENZO FERNÁNDEZ 1948: 168) o en el XIV (CHAMOSO LAMAS 1955: 57).

\subsection{La leyenda de Santa Mariña y su fijación en el territorio}

La leyenda de Santa Mariña ya ha sido tratada en detalle por otros autores (BARANDELA RIVERO \& LORENZO RODRÍGUEZ 2011; GARCÍA QUINTELA 2014a; 2014b) y nos limitaremos a los aspectos relacionados con el presente trabajo, en paralelo con otros que relacionan la leyenda con la cristianización del paisaje de Augas Santas (GARCía QuINTELA \& SEOANE-Veiga 2011). Para atender a estas hipótesis indicaremos las fuentes documentales y bibliográficas que se han ocupado de la leyenda.

No sabemos con exactitud el momento en el que surge en la Península Ibérica la advocación a Santa Marina. En Augas Santas su historia se atestigua desde el siglo XVI (MoRALES 1574: 384 385; Molina 1675 [ed. original 1550]: 17-189 ). Es más detallado el texto de Fr. Juan Muñoz de la Cueva $(1719 ; 1726)$, obispo de Ourense, en las que se recoge el relato de su vida y martirio, que se resume en que "Era hija de Theudio, gobernador y sacerdote pagano de Xinzo, [...] Cuando tenía quince años, el emperador Adriano envió a Galicia un «presidente» llamado Olibrio que encontró a Mariña casualmente. Prendado de su hermosura, intentó hacerla suya pero fue rechazado, entonces Olibrio apresó a Mariña y la envió a Armea, donde fue torturada hasta su muerte por decapitación” (GARCÍA QuINTELA 2014a: 61).

En Augas Santas los episodios de la vida de Santa Mariña se relacionan con diferentes lugares, de manera que la leyenda del martirio se dispersa por el territorio. En este contexto el Forno conmemora el martirio por fuego de la santa (supra n. 5), hecho reforzado por la presencia de tres piletas ${ }^{10}$ labradas en un afloramiento de granito situado a los pies del Outeiro dos Pendóns identificadas como el lugar en donde San Pedro habría reconfortado a Mariña tras librarla del fuego y a las que se atribuyen propiedades curativas. Otros lugares de la parroquia se relacionan con vivencias de la Santa y sus capacidades curativas. Son robles, rocas y aguas en una síntesis de elementos naturales cuyo culto por los primitivos cristianos de Gallaecia denunciaba Martín de Dumio (De correctione rusticorum) (GARcía Quintela \& SEOANE VeIGA

\section{1; 2013; GARCía QUINTELA 2014a; 2014b).}

\section{LECTURA DE PARAMENTOS DEL CONJUN- TO ARQUITECTÓNICO}

Para determinar la evolución constructiva del conjunto empleamos el análisis estratigráfico de paramentos (BrogIOLO 1988; CABALlERO ZOREDA 1995; 1996; PARENTI 1995). Se identificaron 122 unidades estratigráficas (UE) agrupadas en 23 actividades (A) y seis fases constructivas (Tabla 1, Fig. 11).

\subsection{Fase I}

Los restos de la fase I se localizan en la cripta y se vinculan a dos actividades. La A101 (UE037, U038, UE041, UE046, UE074) se corresponde con la construcción de un sistema de acopio y evacuación de agua, formado por un corte del sustrato rocoso, de sección en "V" con la base recta, que en el extremo occidental es más ancho, a modo de balsa, y se va estrechando en un canal que en el último tramo es de sección rectangular y tiene las paredes revestidas de pequeña mampostería, con los mampuestos muy redondeados y las juntas enripiadas, y está cubierto por losas de granito. El canal pasa por debajo del altar, del muro este de la cripta, para salir $7 \mathrm{~m}$ más allá de los límites del edificio. Aproximadamente debajo del altar en la pared norte del canal se documenta un caño de granito que está obturado. Debajo del altar hay una losa con un agujero circular que comunica con el canal.

La A102 (UE051?, UE053, UE054, UE057, UE059, UE061?) corresponde con el forno, su suelo y el de la cámara rectangular (Fig. 7). El forno es una estructura de planta circular con aparejo de mampostería irregular de pequeño-mediano tamaño (las piezas mayores se sitúan en la parte superior), formada por mampuestos bastante redondeados, con las juntas enripiadas y con restos de mortero. La estructura forma una bóveda por aproximación de hiladas que remata en una losa con un agujero central redondeado muy similar a la de la A101 (UE046) sellado por una piedra. El vano de acceso al forno va curvando hacia la parte superior y está rematado por un dintel formado por una gran losa sin carear. Las jambas están formadas por grandes bloques dispuestos en sentido horizontal. Apoyada en el frente del forno en el lado norte del vano, hay una gran losa de granito (A102, UE053) sobre la roca cortada, con la cara redondeada; en el lado sur debía haber otra de características similares que está cortada (A102, UE054). La

\footnotetext{
9 "Está su cuerpo en una iglesia, que es a dos leguas de la ciudad de Orense, cerca de ciertos edificios, y grandes poblaciones antiguas, que están destruidas, que llaman Antiochia; están allí junto a aquella iglesia hoy día unos hornos debajo de la tierra, que para ir a donde ellos están entran por unas escaleras hechas unas bóvedas, en las cuales estando, ardiendo fue metida, esta bendita virgen, mas luego se salió milagrosamente por un agujero muy pequeñísimo... y siéndole cortada la cabeza, donde cayó, salieron tres fuentes en tres partes, las cuales están allí ahora junto de la iglesia, a la cual se tiene gran devoción, porque ha habido milagros conocidos, y hay en ella gran romería" (MoLina 1675: 17-18).

${ }^{10}$ Pías en gallego. La Pila de Santa Marina (CALvo 1913: 350).
} 
parte superior de la estructura ha sido reformada posteriormente. El suelo de esta estancia ${ }^{11}$ y de la pieza rectangular adyacente está realizado con grandes losas de granito irregulares y otras cortadas a regla. Tanto el suelo del forno como las paredes están ennegrecidos y sobre las paredes hay una capa blanquecina que podría corresponder a la formación de líquenes y hongos.

Se ha documentado también la A103 (UE012, UE013, UE067) que se corresponde con los restos de varios muros en el alzado norte del sector 2 de la cripta, pero no contamos con elementos de datación para poder adscribirlos a la fase I o la II, aunque son anteriores a la construcción de la cripta (fase IV). Se trata de dos muros (A103, UE012, UE013) situados a los lados de los últimos peldaños de la escalera norte (tramo 2, sector 2) cortados por esta y por los arcos fajones, que sólo conservan dos hiladas y están realizados con sillares y bloques irregulares, con las juntas muy anchas y enripiadas, el del lado este levantado sobre un zócalo. Además, también incluiría la parte baja del muro norte del tramo 3 (sector 2) formada por la roca cortada (A103, UE067) sobre la que se dispone la bóveda apuntada (A106, UE021).

\subsection{Fase II}

En esta fase se construye la estancia rectangular del sector 3 y un nuevo sistema de canalización (A104, UE022, UE023, UE025, UE027, UE033, UE034, UE035, UE036, UE044?, UE049, UE050, UE055, UE0256, UE071). La estancia se cierra por el este con una gran losa de granito pentagonal que incluye un vano de escasa altura $(1,47$ $\mathrm{m}$ de alto x $0,63 \mathrm{~m}$ de ancho) cortado en la propia losa, de jambas rectas, rematado en un arco de medio punto y enmarcado por un rebaje rectangular donde se han abierto tres agujeros para el encaje de un sistema de cierre. A los lados del vano hay dos relieves y varias cruces grabadas. Las paredes laterales están realizadas en sillería, con sillares cortados a regla, algunos de los cuales presentan los lados dovelados, codos o las esquinas rotas. Algunas piezas son irregulares, sobre todo en la parte inferior oeste del muro norte, y más parecen bloques que sillares. Se conservan seis hiladas en el muro sur y siete en el norte. Las hiladas unas veces son inclinadas, otras ondulan, acodan o doblan. Las juntas son finas, sobre todo las horizontales, carecen de ripios y en alguna zona se aprecian restos de mortero (Fig. 12). Sobre los muros descansa una bóveda que pertenece a una fase posterior (A105, UE026, UE048). Los muros se apoyan en la gran losa, el forno y el enlosado. Reciente- mente se produjo un destrozo intencionado y se quitaron algunas de las piedras de la fachada de esta antecámara (al norte de la gran losa de entrada), en concreto un sillar cuadrangular, lo que nos permitió ver el interior del muro. Entre el corte del sustrato rocoso y el muro UE050 se dispone un relleno de tierra, argamasa y piedras, que está forrado por el muro de sillería que acabamos de describir. De este relleno se recogió una muestra para datación (MU05002) (Fig. 15) cuyos resultados presentaremos más adelante.

La fachada de este espacio incluiría muros situados a los lados de la losa pentagonal pero de menor altura. Al sur consiste en una losa de granito de la que sale un caño que vierte sobre un depósito de agua, y al norte un muro de bloques y un gran sillar reutilizado que se asientan sobre la roca cortada (A103, UE067). La losa sur hace esquina con otra igual que forma el muro sur del tramo 3 (sector 2). Ambas envuelven un depósito de agua de planta rectangular, semienterrado, formado por grandes losas de granito similares a la empleada en la pared que hemos vinculado a esta misma fase. La boca del caño corresponde a una reforma ${ }^{12}$, pero la canalización realizada con piezas de granito de sección en U se introduce por dentro del muro, gira hacia el sur y luego hacia el oeste. De la parte baja del depósito sale un canalillo (A104, UE071) en dirección noreste que corta la primera canalización (A101, UE037, UE074) y que luego gira hacia el este hasta verter en el canal construido con mampostería (A101, UE038). Tiene sección en "V" con la base recta.

\subsection{Fase III}

A esta fase corresponde una bóveda de cañón de medio punto construida sobre la estancia rectangular de la fase II (A105, UE026, UE048, UE058, UE062, UE063, UE065) (Fig. 6 arriba). La bóveda descansa sobre una moldura formada, de arriba abajo, por una nacela decorada con bolas, media caña y filete ${ }^{13}$ y está realizada en sillería de granito con los sillares cortados a escuadra dispuestos en hiladas horizontales regulares que se van estrechando hacia la clave. Las juntas son finas, carecen de ripios y se aprecia un posible mortero o tierra. La bóveda se encuentra a una cota más baja que las que cubren los tres tramos del sector 2. Para disponer el arranque de la bóveda se han cortado los extremos superiores izquierdo y derecho de la gran losa de la fachada este de la antecámara y la losa de la pared del depósito. Algunos de estos sillares están inclinados para adaptarse al plano inclinado de la parte suprior de la propia losa en la que se

\footnotetext{
${ }^{11}$ Sobre el suelo del forno se localiza una pieza de granito con agujero central redondeado similar a los documentados en el remate de la bóveda del forno y el

${ }_{12}$ Posterior a la intervención de Chamoso Lamas ya que en las fotografías de la cripta conservadas en su fondo documental de la Real Academia Gallega de Bellas Artes (http://www.academiagallegabellasartes.org/galeria.asp?Pagina=6\&par=si9 estaba prácticamente a paño con la pared. En esta imagen el depósito estaba lleno de agua y se aprecian en el enlosado delante de la Pedra Formosa tapas de sarcófago como suelo. Ver también LORENZO FERNÁNDEZ 1848: 179. ${ }^{13}$ La moldura presenta bastantes roturas.
} 

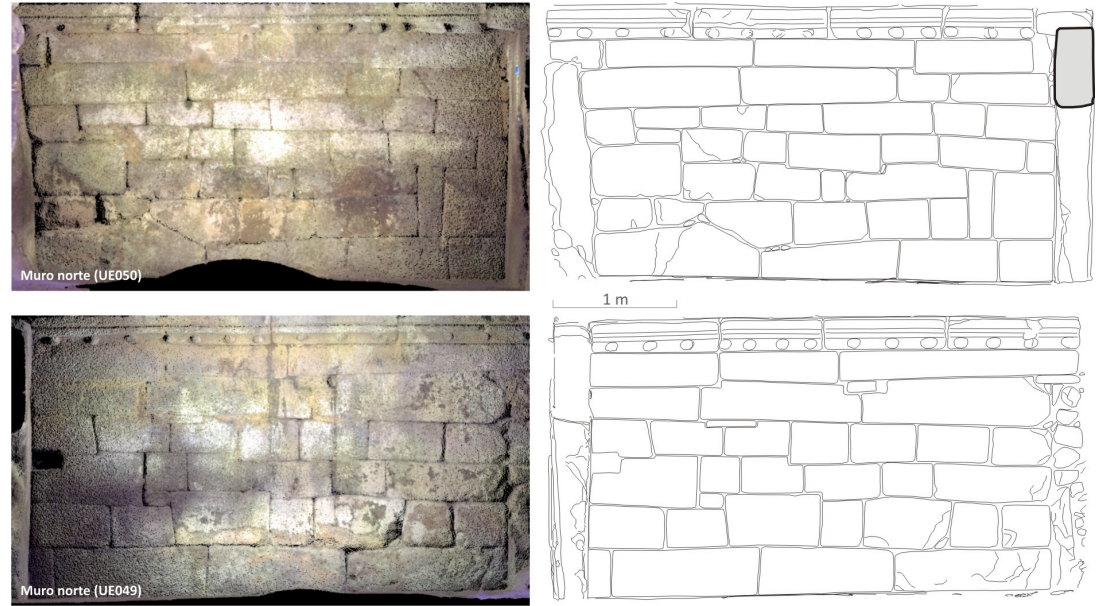

Fig. 12. Detalle de la sillería empleada en la estancia que antecede al forno. A la izquierda, nube de puntos obtenida a partir del escaneado; a la derecha dibujo realizado a partir de la nube de puntos. Fig. 12. Detail of the stonework employed in area before the "oven". To the left, point cloud obtained from scanning; to the right, drawing made from the point cloud.
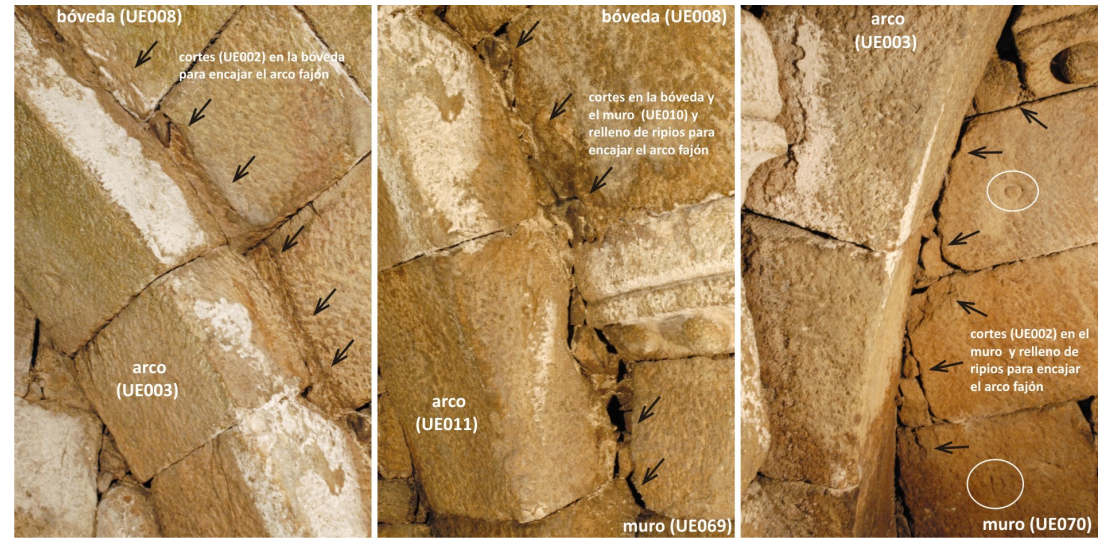

Fig. 13. Cortes practicados en las bóvedas y muros del sector 2 para encajar los arcos fajones. Fig. 13. Cuts made in the vaults and walls of the sector 2 in order to fit the transverse arches.

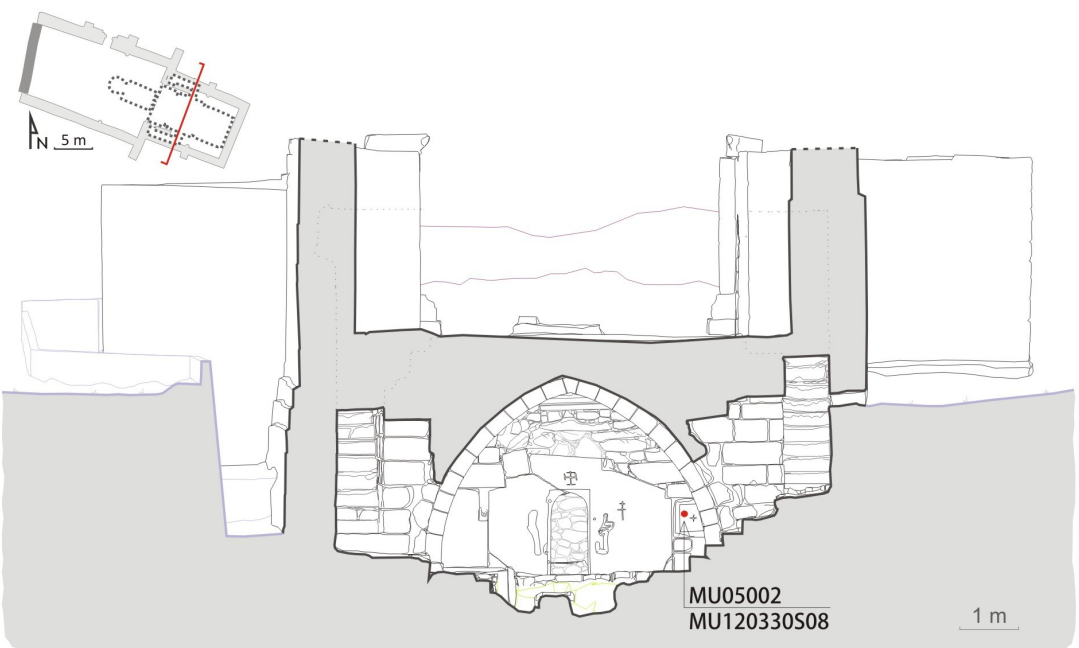

Fig. 14. Sección Sur-Norte del conjunto de la basílica de la Ascensión y Os Fornos, obtenida a partir del escaneado, en el que se ha marcado la localización de la muestra MU05002/ MU120330S08 extraída del interior del muro.

Fig. 14. Section South-North of the complex, obtained from scanning, showing the location of the MU05002/MU120330S08 sample extracted from the inside of the wall. 

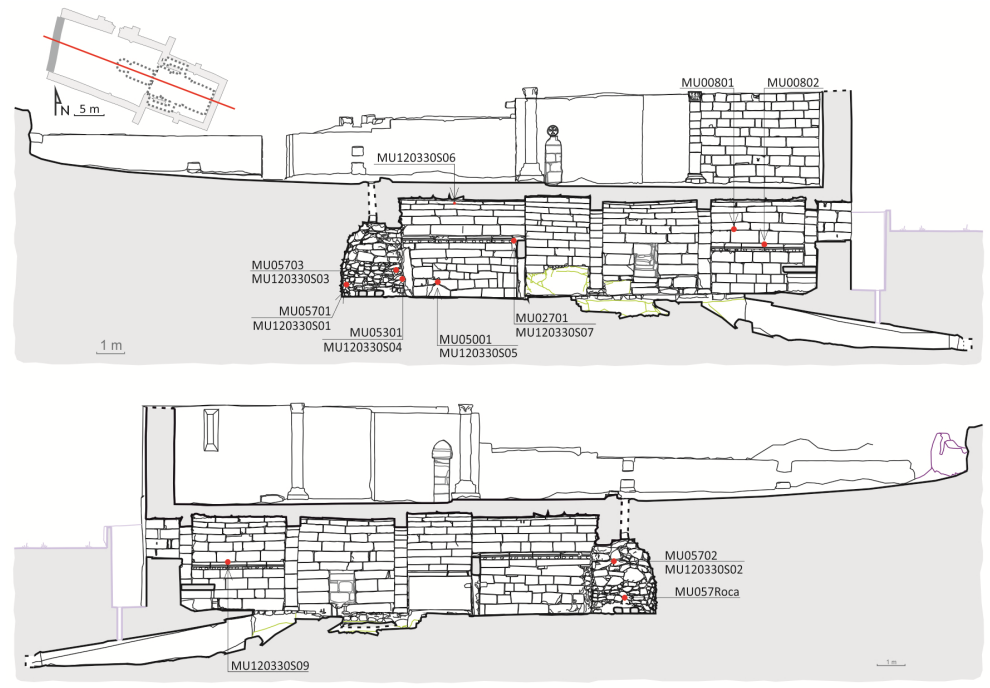

Fig. 15. Secciones longitudinales del conjunto y localización de las muestras extraídas en la cripta, conjuntamente con la que se muestra en la Fig. 14.

Fig. 15. Longitudinal sections of the basilica, and location of the samples extracted from the crypt, together with the one shown in Fig. 14.

apoyan. También se eleva la "cúpula" del forno hasta llegar al intradós de la bóveda, empleando un aparejo de mampostería que imita al anterior en el que se reutiliza una moldura de granito igual a la empleada en la bóveda de esta misma fase, aunque carece de las bolas.

\subsection{Fase IV}

Esta la reforma más importantes del conjunto y la que le proporciona su aspecto actual (Fig. 4). Hemos distinguido dos etapas ligeramente diferentes aunque no parecen variar el programa constructivo inicial.

\subsubsection{Etapa IVa}

Corresponden a esta etapa la construcción de la cripta (A106, UE001, UE008, UE009, UE014, UE020, UE021, UE031, UE066, UE068, UE069, UE070), la escalera norte de bajada a la cripta (A107, UE113, UE114, UE115, UE116, UE120, UE121) y la sur (A108, UE017, UE102, UE103, UE104?, UE106, UE0107), y la iglesia (A109, UE076, UE088, UE091, UE092, UE093?, UE094).

La cripta se construye delante del espacio formado por el forno y la sala rectangular (sector 3) y se articula en tres tramos (Fig. 5). El más oriental hace de ábside por la presencia de un altar, tiene los muros de sillería dispuesta en hiladas horizontales muy regulares $^{14}$, con sillares cortados a escuadra, juntas finas sin enripiar y con algún resto de mortero. Se documentan dos tipos de marcas de cantero ("o", "+" con los extremos en triángulo). Tienen una moldura con bolas igual a la de la fase III, también con abundantes roturas, situada a mayor altura en la pared este. Los extremos de los muros están cortados para disponer unos arcos fajones. En la pared este de localiza la única ventana cuya parte superior está parcialmente tapada por el arco fajón que se apoya en el muro este. Sobre la moldura descansa una bóveda de cañón apuntada con clave descentrada que presenta el mismo aparejo que los muros. El segundo tramo incluye los accesos a las escaleras. Es un espacio abovedado con bóveda de cañón apuntada que nace en el suelo en el lado sur y sobre unos muros anteriores (A103, UE012, UE013) en el norte. El aparejo es igual al de la bóveda del primer tramo, aunque con doble clave. También se aprecian cortes en las partes bajas de la bóveda y rebajes en las altas para encastrar los arcos fajones. El tercer tramo también tiene una bóveda de cañón apuntada de sillería igual a las anteriores. En el lado sur se apoya en una moldura cortada en chaflán dispuesta sobre la losa de la fase II (A104, UE022) y en el norte sobre la roca cortada (A103, UE067) de la fase I o II regularizando el apoyo con ripios. La clave está descentrada.

Las dos escaleras están realizadas con muros de sillería de granito que presentan las mismas características y marcas de cantero que las de los muros del primer tramo del sector 2. Los peldaños y la cubierta escalonada son también de sillería de granito.

En el apartado 1.1. hemos descrito la iglesia y ahora incidiremos en tres aspectos. Por una parte, no se han apreciado cortes indicativos de una construcción en varias fases, únicamente se aprecian alteraciones que corresponden a las últimas fases detectadas en el edificio (A116, UE087; A120, UE086). Por otra parte, los muros de la iglesia que tienen dos caras y relleno (Fig. 8), presentan las mismas características que los muros de la cripta,

\footnotetext{
${ }^{14}$ Nos referimos a la regularidad de la horizontal de la hilada, no a la altura de las hiladas que es variable, oscila entre los $0,30 \mathrm{y}$ los $0,42 \mathrm{~m}$ de alto.
} 
con ligeras diferencias en algunas partes: reutilización de materiales, cortes dovelados y pequeños codos o hiladas que doblan, sobre todo en zonas de encuentro de dos muros, pero no podemos decir que se aprecien interfaces constructivas. Finalmente, además de las marcas de cantero documentadas en la cripta, se aprecian también una "I" con los extremos en triángulo y una especie de lazo ${ }^{15}$.

\subsubsection{Etapa IVb}

En esta etapa se reforma el suelo de la cripta (A110, UE042, UE043, UE045, UE072, UE073, UE075) sobre la segunda canalización (A104, UE071) que parece corresponder a la preparación de un nuevo suelo con una base de mampostería cubierta por un enlosado. También se refuerzan las bóvedas mediante cuatro arcos fajones, tres separan los tres tramos y el cuarto se apoya contra el muro este (A111, UE002, UE003, UE004?, UE010, UE011, UE018, UE019, UE028?, UE030?, UE032). Aunque no creemos que exista una gran separación cronológica con la etapa anterior, varios detalles llevan a pensar que los arcos no son coetáneos a las bóvedas: los cortes documentados en los alzados y bóvedas en las que se encastran o el relleno existente entre los arcos y las bóvedas y entre los arcos y las paredes que se observan en algunas zonas (Fig. 13). A nuestro modo de ver si los arcos fuesen coetáneos a las bóvedas se harían ajustados a estas y no habría que rellenar el espacio que existe entre ellos. Por otra parte, gracias al escaneado pudimos comprobar que las bóvedas están desplomadas en muchas zonas, por lo que entendemos que fue necesario su refuerzo tal vez tras iniciarse la construcción de la iglesia.

\subsection{Fase $\mathbf{V}$}

Corresponden a esta fase reformas y reparaciones puntuales: la construcción de un altar (A112, UE007) adosado al muro este de la cripta (Fig. 5) con materiales reutilizados como sillares con las mismas marcas de cantero que las de la fase IVa. Se documentan cortes, grietas y roturas en la cripta, escaleras e iglesia reparados con morteros (A113, UE029, UE052, UE082?, UE095?, UE111, UE112?, UE119, UE122); la disposición de una reja en la ventana (A114, UE005, UE006); reformas en las escaleras (A115, UE015, UE016, UE083, UE108, UE110, UE118) y, finalmente, la construcción de un muro de cierre por el oeste de la iglesia (A116, UE087), realizado en mampostería tendente a formar hiladas. El muro sostiene la terraza que ha motivado su construcción.

\subsection{Fase VI}

Esta fase corresponde a las intervenciones arqueológicas. Vinculamos a la fase VI una serie de cortes, agujeros y reparaciones con mortero de cemento que se documentan en la cripta y las escaleras norte y sur (A119, UE064, UE077, UE105, UE109, UE117). Así como las grietas de asiento identificadas en varios muros exteriores del conjunto (A122, UE079, UE080, UE081, UE084, UE085).

\subsubsection{Etapa VIa}

Se cierra el agujero de ventilación del forno con una piedra de granito (A117, UE060); se reforma el suelo de la cripta con la construcción de un enlosado para rellenar los huecos dejados por el levantamiento de las tapas de sarcófago y molduras (A118, UE039, UE040); y se efectúa una reconstrucción en la zona oeste de la fachada sur de la iglesia con mampostería irregular de granito dispuesta a hueso (A120, UE086).

\subsubsection{Etapa VIb}

Finalmente, la etapa IVb se corresponde con la construcción de una zanja (A121, UE078, UE090) que rodea el lateral sur y parte del este del ábside, construida con hormigón y que tiene como objetivo desviar el agua que vertía en el interior de la cripta hacia el canal que sale por debajo del muro este de la misma.

\section{RESULTADOS DE LAS ANALÍTICAS DE MOR- TEROS Y SUELOS}

En la fase 2 de los trabajos se recogieron muestras de morteros en la cripta y de los suelos del entorno de la iglesia con la intención de caracterizarlos y datarlos. Los resultados de estos trabajos están en proceso de análisis y serán objeto de publicaciones específicas. Nos limitaremos a adelantar los resultados que tienen que ver con la datación absoluta de las fases identificadas centrándonos en la transformación del edificio primitivo en un edificio de uso cristiano.

Se recogieron 10 muestras de morteros, 9 de mortero de tierra y 1 con ligante de cal o cemento para datarlos por OSL (Tabla 2); tres no pudieron datarse (MU05702, MU00802A y MU05702).

Las muestras MU05701, MU05703, MU05301 (Fig. 15) se recogieron en las paredes del forno, en un mortero de junta muy plástico de coloración negruzca, con la intención de datar la estructura que, según la estratigrafía y los estudios llevados a cabo hasta la fecha, es la más antigua de todo el conjunto. La cronología oscila entre el $1411 \pm 17$ d.C. (MU05301), el 1459 24 d.C. (MU05701) y el $1642 \pm 19$ d.C. (MU05703) (Tabla 3$)^{16}$, es decir, entre finales del siglo XIV-principios del siglo XV y mediados del siglo XVII.

El segundo grupo de muestras se recogió en

${ }_{16}^{15}$ Las cuatro marcas se suelen relacionar con la posición de los sillares.

${ }^{16}$ Dataciones obtenidas en el Laboratorio de Datación por Luminiscencia de la Unidad de Geocronología (Instituto Universitario de Xeoloxía Isidro Parga Pondal, Universidade de A Coruña). 
Tabla 2. Descripción breve de las características de las muestras de morteros analizadas. Table 2. Brief description of the characteristics of the analyzed samples of mortars

\begin{tabular}{|c|c|c|}
\hline Muestra & Localización & Descripción \\
\hline MU02701 & Antecámara muro sur arriba (S3) & Arena media-gruesa predominante \\
\hline MU05701 & Forno lado oeste abajo (S3) & Mezcla de arena fina y arena media \\
\hline MU05702 & Forno lado sur arriba (S3) & Arena media-gruesa predominante \\
\hline MU05703 & Forno lado norte centro abajo (S3) & Mezcla de arena fina y arena media \\
\hline MU05001 & Antecámara muro norte abajo (S3) & Mezcla de arena fina y arena media \\
\hline MU05002 & Interior muro norte antecámara (S2) & Arena media-gruesa predominante \\
\hline MU05301 & Forno lado norte abajo & Mezcla de arena fina y arena media \\
\hline MU008001 & Muro norte tramo 1 S2 & Mezcla de arena fina y arena media \\
\hline MU00802A & Muro norte tramo 1 S2 & Mortero con ligante de cal o cemento \\
\hline MU00802B & Muro norte tramo 1 S2 & Mezcla de arena fina y arena media \\
\hline
\end{tabular}

Tabla 3. Edades finales de los morteros datados por OSL. Table 3. Final ages of the mortars dated by OSL.

\begin{tabular}{|c|c|c|c|}
\hline Muestra & Dosis anual (mGy/a)* & Dosis equivalente (Gy) & Año DC \\
\hline MU02701 & $5.4 \pm 0.1$ & $2.4 \pm 0.2$ & $1612 \pm 19$ \\
\hline MU05701 & $6.2 \pm 0.1$ & $4.6 \pm 0.5$ & $1459 \pm 24$ \\
\hline MU05702 & $7.4 \pm 0.1$ & - & - \\
\hline MU05703 & $6.3 \pm 0.1$ & $1.9 \pm 0.1$ & $1642 \pm 19$ \\
\hline MU05001 & $6.2 \pm 0.1$ & $2.7 \pm 0.1$ & $1580 \pm 14$ \\
\hline MU05002 & $6.6 \pm 0.1$ & $9.9 \pm 0.6$ & $548 \pm 45$ \\
\hline MU05301 & $6.3 \pm 0.1$ & $3.9 \pm 0.2$ & $1411 \pm 17$ \\
\hline MU00802B & $6.6 \pm 0.1$ & $2.3 \pm 0.2$ & $1618 \pm 11$ \\
\hline
\end{tabular}

la sala rectangular del sector 3 en cuyos muros también se documentaron morteros en las juntas similares a los anteriores, aunque de una coloración más clara. La MU02701 dio una datación de $1612 \pm 19$ d.C. y la MU05001 de $1580 \pm 14$ d.C. La fecha no corresponde con la hipótesis que vinculaba este muro a la Alta Edad Media (LORENZO FERNÁNDEZ 1948: 172; CHAMOSO LAMAS 1955: 60) y que estratigráficamente se situaba entre el forno y la construcción de la cripta. Pero pudimos recoger una muestra del interior del muro MU05002 (Fig. 14), que dio una datación de $548 \pm 45$ d. C., es decir, data la construcción de la antecámara en el siglo VI.

Finalmente, el tercer grupo se recogió en el primer tramo de la cripta, donde también documentamos morteros en la junta de apariencia muy similar a los de la antecámara. Únicamente se pudo datar la MU00802B que dio $1618 \pm 11$ d.C. Esta fecha coincide con la de otros morteros de junta de la antecámara y el horno.

Los morteros datados corresponden en su mayoría a morteros de junta y únicamente uno de ellos se pudo tomar en el interior de un muro que corresponde con la fase II de la secuencia documentada. En el primer caso, los morteros no se introducen en la junta, sino que se localizan superficialmente, lo que nos lleva a plantear que no son originales al momento de la construcción de los muros en los que se recogieron. Es decir, durante la baja edad media y la edad moderna se documentan actividades en la cripta que coinciden, por una parte, con el final de su construcción y, por otra, con las menciones que se hacen a la leyenda de Santa Mariña en diferentes fuentes. Parece que estas actividades conllevan el rejuntado de los muros, que se restauran en varios momentos. En el segundo caso, únicamente se ha podido datar la fase constructiva II que corresponde al siglo VI momento en el que proponemos una reforma de un edificio del que conservamos sólo algunas partes, como veremos.

Por otra parte se realizaron 5 sondeos de suelos de los terrenos adyacentes, las dataciones obtenidas remiten a fechas correspondientes a la fase III y a la plena Edad Media, por lo que su consideración queda fuera de nuestros objetivos, y serán tratadas en otro trabajo. 


\section{ARGUMENTACIÓN CRONOLÓGICA Y CUL- TURAL: DE SAUNA DE LA EDAD DEL HIE- RRO A IGLESIA INCONCLUSA}

La secuencia que hemos visto en el apartado anterior establece cuatro grandes etapas constructivas en el monumento (Fig. 16) que, a su vez, marcan el ritmo de la reutilización de este espacio y su reinterpretación a lo largo de los siglos.

El origen del conjunto monumental se remonta a la Edad del Hierro y está en relación con el adyacente castro de Armea. La cripta, el forno y el suelo de la sala rectangular son los espacios más antiguos. Las saunas meridionales (ver supra $\mathrm{n}$. 4) consisten en cuatro estancias dispuestas longitudinalmente: la entrada con depósitos de agua y un canales de traída y de desagüe, una sala fría o antecámara, la sala de vapor en sentido estricto y el forno con su singular planta, además destaca la utilización de grandes losas graníticas en la construcción. Separando la sala fría de la sala de vapor aparece una gran pieza monolítica pentagonal conocida como pedra formosa, según la denominación tradicional dada en Briteiros (Portugal) a la primera pieza documentada de estas características (GARCÍA QUINTELA \& SANTOS ESTÉVEZ 2015: 71) (Fig. 17).

Los elementos identificados en la fase I de cripta de Os Fornos remiten a una sauna del grupo meridional: disposición longitudinal de la planta, el depósito y el canal de desagüe en el atrio, la pedra formosa probablemente modificada y desplazada, la estructura de la sala de vapor y el forno y su enlosado con grandes piezas graníticas. En la descripción del forno señalábamos la presencia a su entrada de dos grandes losas verticales, apoyadas contra éste (rota la del lado sur). Aunque desconocemos su funcionalidad señalamos otros casos similares en las saunas portuguesas de Alto das Eiras (Vila Nova de Famalicão), Briteiros 2 (Guimarães) o Sanfins (Paços de Ferreira).

Sin embargo, la pedra formosa y el depósito no mantienen ninguna relación estratigráfica con los elementos seguros de la fase I. Es probable que la primera se haya desplazado al construirse la sala rectangular a partir de la sala de vapor en la fase II. Además, si la sauna original seguía el modelo meridional, esta reforma hace desaparecer la "antecámara" del edificio primitivo. Por otra parte, el vano de acceso se amplió pues en las pedras originales el paso solo es posible arrastrándose. También pudieron añadirse las cruces, aunque estas también se atestiguan en saunas sin transformación cristiana (Santa María de Galegos en Barcelos, o Briteiros 2 en Guimarães, ambas en Portugal), pero con una tipología diferente. Por otra parte, la cruz que se encuentra sobre el vano de la pedra del Forno da Santa es semejante a las cruces grabadas en una ara romana localizada en Augas Santas, conservada en la iglesia parroquial, reutilizada como pie de altar (Fig. 18).
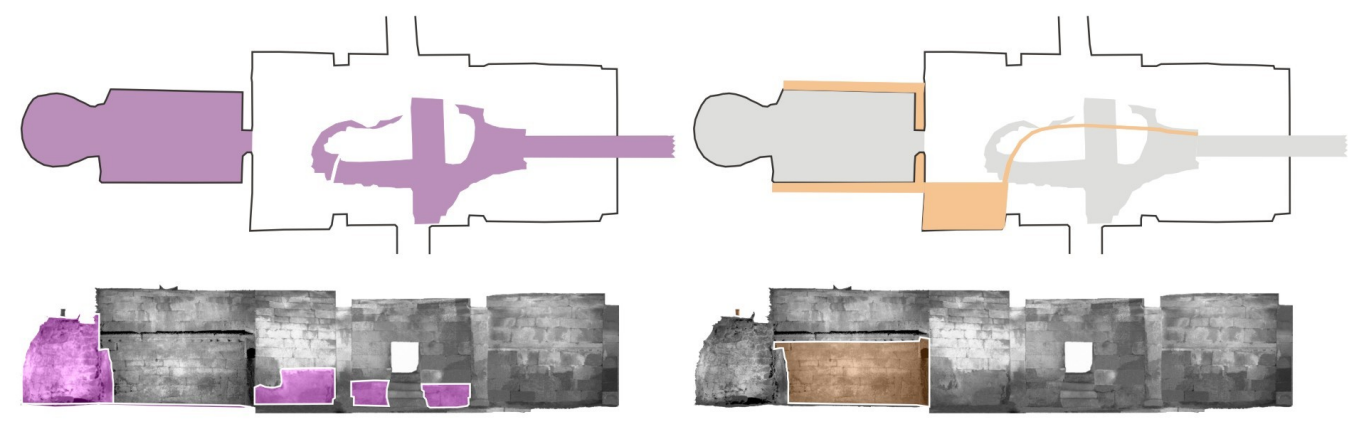

Fase I: Edad del Hierro

Fase II: Alta Edad Media (siglo VI)
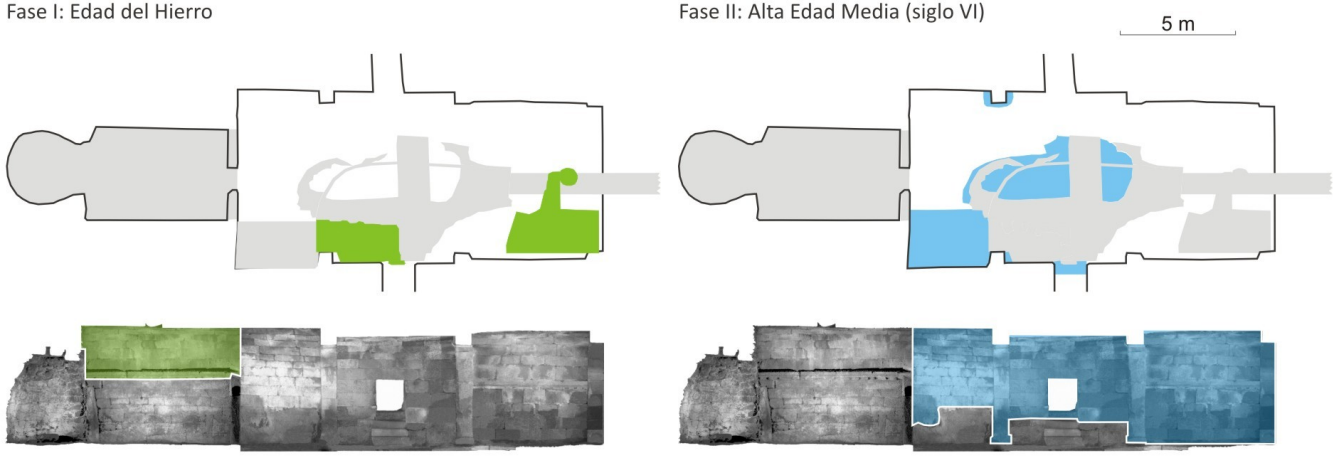

Fase III: siglo XII

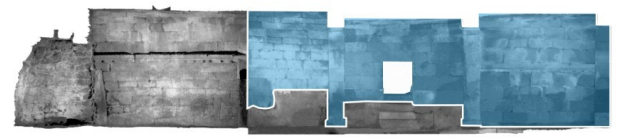

Fase IV: finales del s. XIII - principios del s. XIV

Fig. 16. Evolución constructiva de la cripta de la basílica de la Ascensión. Se han marcado las fases constructivas sobre la planta y el alzado norte.

Fig. 16. Evolution of the crypt of the basilica of Ascension. We have marked on the floor and the wall North the construction phases. 


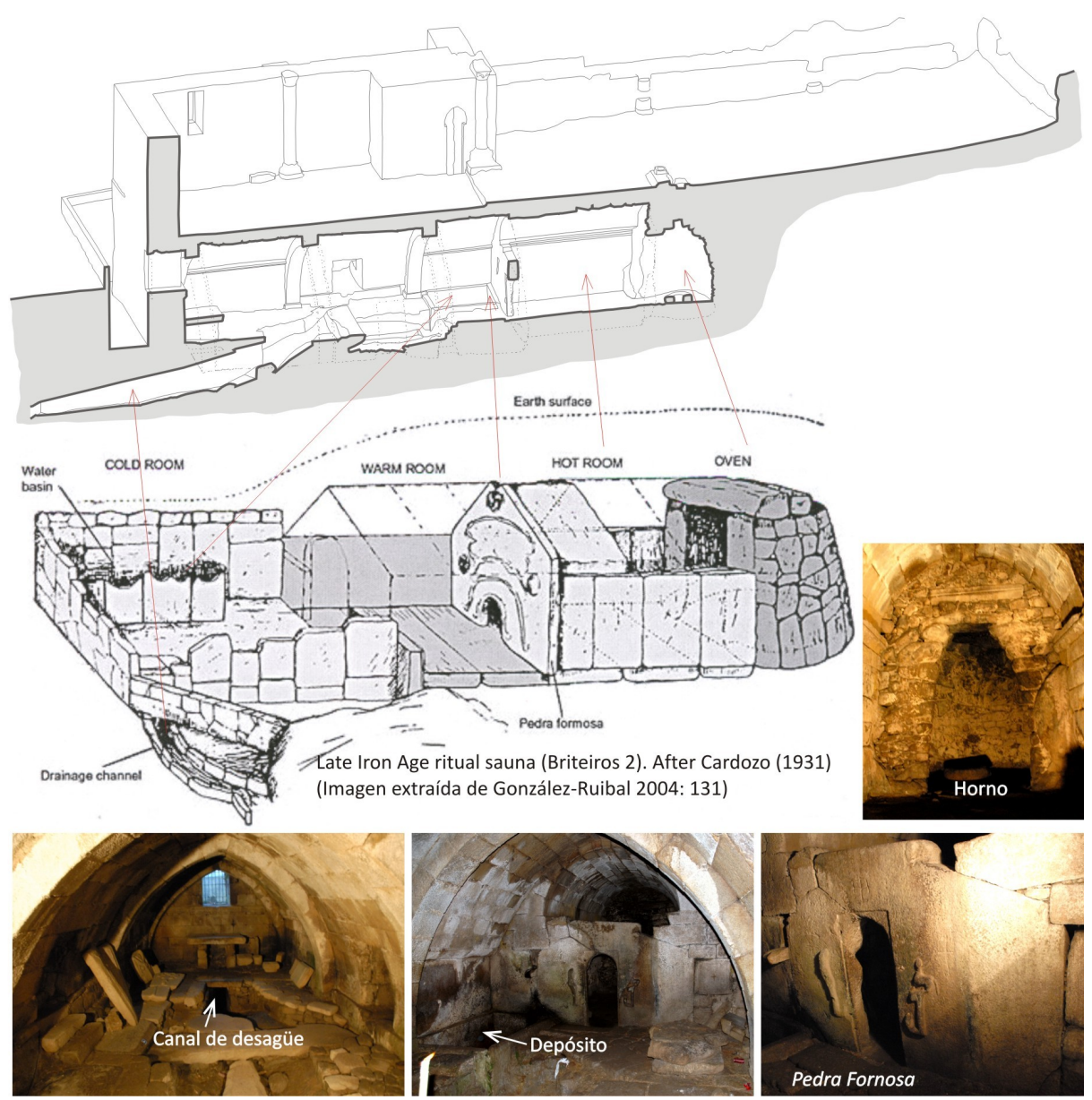

Fig. 17. Diferentes elementos conservados en la cripta que son representativos de una sauna de la Edad del Hierro.

Fig. 17. Different elements stored in the crypt that are representative of an Iron Age sauna.

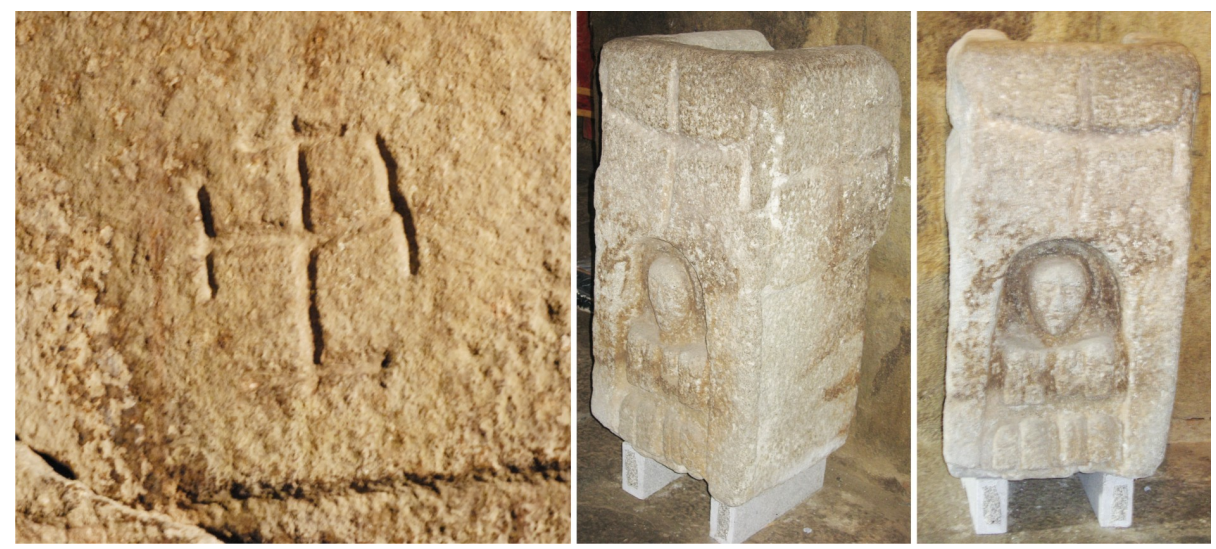

Fig. 18. A la izquierda, cruz grabada en la Pedra Formosa; a la derecha ara aparecida en Armea reutilizada como pie de altar que tiene grabada una cruz similar en la parte alta.

Fig. 18. To the left, sculpted cross in the Pedra Formosa; to the right, ara from Armea, reused as foot of altar, with a similar cross carved on the top.

El depósito de agua se sitúa estratigráficamente en la fase II, pero no podemos saber si existía en este mismo lugar o en otro un depósito similar en la fase I.
Este análisis corrobora la hipótesis sobre el origen del Forno da Santa en una sauna de la Edad del Hierro, aunque el estudio estratigráfico no permita establecer la posición original de todos ellos 
debido sobre todo a la probable amortización y desaparición de una de las dependencias originales. Por otro lado, pese a los esfuerzos por lograr una datación absoluta del forno, su posición soterrada en una zona con niveles freáticos altos, con presencia permanente de agua en el monumento y la permeabilidad de materiales desde el exterior hacia el interior de los muros, y las reposiciones de morteros de épocas bajomedieval y moderna, han imposibilitado determinar su cronología, más allá de una fecha ante quem al siglo VI, momento en que se han datado los muros de la antecámara que se apoyan en el forno.

La segunda fase corresponde a una reforma altomedieval. Se construye delante del forno una estancia rectangular con muros de sillería cuya tipología es similar a la de otros aparejos documentados en el entorno como la cabecera de Santa Eufemia de Ambía (Baños de Molgas), aunque con un módulo menor, que ha sido fechada por algunos autores en época visigoda (RIVAS FERNÁNDEZ 1971; CASTIÑEIRAS GONZÁLEZ 1990) y por otros en el siglo X (NUÑEZ 1978: 322). Por su parte Lorenzo (1948: 172) y Chamoso (1955: 60) consideraban los muros de esta fase prerrománicos. A partir de aquí nuestra hipótesis es que se trataba de una reforma altomedieval. La estructura aprovecha el forno del extremo oeste, seguido por el espacio rectangular que tendría como fachada la pedra formosa desplazada y modificada. Los cortes practicados en la parte superior parecen pensados para encajar una cubierta a dos aguas y disponer una pequeña espadaña $\mathrm{o}$, más probablemente, una cruz sobre pedestal central (Fig. 6). En este momento sería un edificio semienterrado, también según el modelo de las saunas meridionales.

Los muros de esta sala se construyen apoyados contra el corte del sustrato rocoso, con un relleno de mortero de tierra y piedras y un forro de sillería. Este relleno se ha datado en el siglo VI, fecha que retrasa la hipótesis inicial pero que encaja con propuestas que ven en la historia de Mariña y su fusión con el paisaje un vector de cristianización utilizado conscientemente. Sabemos que en Augas Santas "una serie de monumentos y restos diversos [son] considerados como otros tantos testimonios fidedignos de las obras, padecimiento y milagros de la santa. Cosa que ocurría en tiempos de Muñoz de la Cueva y en la actualidad, pues esas tradiciones están vivas entre los vecinos que nos relatan una y otra vez con una extremada fidelidad a lo contado por la tradición letrada" (GARCÍA QUINTELA 2014a: 61), pero posiblemente provendrían de una tradición anterior. García Quintela $^{17}$ baraja la hipótesis de que el culto habría sido introducido por Hidacio (395-470) obispo de Cha- ves originario de la Limia (región que engloba a Augas Santas) o sus sucesores. Al primero le podría servir para la preparación espiritual de sus fieles ante la creencia en el inminente fin del mundo (BURGESS 1993). Los segundos, tras comprobar que tal fin del mundo no se produjo, podrían haber emprendido la reforma material de los lugares relacionados con la Santa en la fecha indicada para conmemorar un episodio de su martirio:

No se moderò el furor frenético de Olibrio, à vista de tan grande mortandad, antes mas encarnizado, y colerico, bramaba como león ; y mandò, que arrojassen, y cerrassen à la Santa en uno de los hornos, que servian y ardian en el Castillo de Armea, pensando que se esta suerte reduciria à cenizas à la que con desprecio de su amor, de sus promesas, y de la autoridad de su oficio, con desdoro, y injuria de sus adorados Dioses, supo, y pudo convertir, y encaminar al Cielo tantos Martyres. Arrojada Marina entre las voraces llamas, estas la respetaron, como à los tres Mancebos en el Horno de Babilonia; o como en Zarza de Oreb supo el fuego prescindir, dexando sin uso la voracidad del ardor, y bañándola solo con los reflexos agradables de la luz. Oy se vèn junto à Armea, y à distancia bien corta de Augas Santas, estos hornos subterraneos, y un pequeño agujero, que sirve de claraboya à una bobeda bien fabricada de piedra; y por èl dice la tradicion, que el Apostol San pedro sacò à Marina del horno. (MUÑOZ DE LA CUEVA 1726: 53-54).

Entre Hidacio y la fecha de la reforma de Armea ( $548 \pm 45$ d. C.), el culto estaría fijado en el paisaje, como se detecta en muchos otros enclaves "mariñianos" del entorno de Xinzo de Limia y la Lagoa Antela y en la misma Augas Santas. La transformación del primer monumento de la Edad del Hierro y el argumento precedente llevan a la tardoantigüedad la introducción de la leyenda coincidiendo con las fechas usuales de origen y difusión del culto a los mártires (THACKER 2002).

Este segundo edificio, por su forma en planta, sería posiblemente una pequeña capilla o un lugar de culto dedicado a Santa Mariña cuyo ábside sería el Forno. Las modificaciones de la pedra formosa o la reutilización del ara como pie de altar con el mismo tipo de cruces, podrían relacionarse con este momento de cristianización del lugar. Nótese, además, que la leyenda sitúa en la sauna el martirio por el fuego de la Santa. Es decir, si la santa es "agua", como indica su nombre, y se ve sometida al fuego, genera vapor reproduciendo estrictamente la función del edificio primitivo que se conocía o recordaba en el momento de su transformación cristiana.

Delante de esta capilla habría una especie de atrio de mayor anchura que el edificio (cuyas pare-

${ }^{17}$ El tema se presentará en el congreso de la SEAC 2015 Rome "Astronomy in Past and Presente Cultures" (http://www.archeoastronomy.org/) en la conferencia "From Hagiography to Celtic Cosmology: the early years of Santa Mariña in Antela lagoon (Ourense, Spain) and the Limici Celtic heritage" de García Quintela y González García.

${ }^{18}$ Sistema similar al empleado en la sala fría en otras saunas portuguesas como Alto das Eiras (Vila Nova de Famalicão) o Santa María de Galegos (Barcelos). Esta sala antecede a la sala de vapor que en Armea se ha transformado en la fase II 
des estarían parcialmente cortadas en la roca o revestidas de losas de granito ${ }^{18}$ ) en el que se localizaría el depósito de agua y los sistemas de canalizaciones identificados para las fases I y II, con un paso sobre el mismo. De alguna manera, se debió mantener el uso del agua de la sauna posiblemente integrado en el culto a Santa Mariña, ya que se trata de un elemento que tiene gran importancia tanto en la leyenda como en el culto que a día de hoy se mantiene en la parroquia.

La tercera fase consiste en una reforma puntual de la cubierta de esta capilla, con la construcción de una bóveda de cañón de medio punto en torno al siglo XII o XIII, que aunque afectó a las partes altas del conjunto anterior y a la pedra formosa, no parece alteró su estructura. Esto indica que en plena Edad Media la capilla seguiría funcionando. La misma moldura de bolas se utiliza en la siguiente etapa como asiento de la bóveda del ábside del sector 2, pero en ambos casos las molduras presentan abundantes cortes que llevan a plantear su posible reutilización.

La cuarta fase oculta los lugares anteriores en una cripta y monumentaliza el lugar con la iglesia inacabada. Los estudios anteriores, las formas de los arcos y bóvedas y las escasas decoraciones con las que contamos llevan el conjunto al siglo XIIIXIV. En todo caso parece que sería anterior a finales del siglo XIV-primer tercio del siglo XV ya que en este momento se datan varios morteros de la cripta, lo que nos lleva a plantear que en la baja edad media se acometen obras que afectan al conjunto. Esta empresa coincide con la construcción de la iglesia de Santa Mariña de Augas Santas en el siglo XIII momento en que el culto a Mariña parece vivir un nuevo impulso.

En Armea se mantienen en la cripta las estructuras anteriores pues la posible capilla que integraría el forno primitivo se incluye en el nuevo conjunto. Lo más significativo es el cambio de orientación del nuevo espacio, ahora con el ábside al este. También se mantendría el uso del agua ya que, por una parte, se conservan canalizaciones y depósito y, por otra, se localizaron depósitos votivos de jarras de cerámica datadas en el siglo XIII (PEREIRA MARIón 1991) ${ }^{19}$. No sabemos en qué momento se colmatan estas estructuras ya que todo el suelo fue intervenido en diferentes etapas.

Sobre esta cripta se edifica la iglesia que dobla las dimensiones de la misma a lo ancho y a lo largo. Para su construcción deben soterrarse las edificaciones previas y se habilitan sendas escaleras de acceso a las mismas, es decir, se diseñó un edificio que acogió y mantuvo viva la tradición anterior.

Aunque no hemos identificado ningún cambio estructural en época moderna, existe un mantenimiento constante de los espacios de la cripta docu- mentados por reposiciones de los morteros de junta en los siglos XVI y XVII indicando un uso constante de la cripta. Estas fechas coinciden con el interés que parece suscitar la leyenda en esos siglos.

En época contemporánea las dos intervenciones más importantes tienen que ver con las excavaciones de Lorenzo Fernández y Chamoso Lamas en las décadas de 1940 y 1950 que alteraron el suelo, pero aportaron importantes datos sobre el edificio, y la construcción en 1962 de una zanja perimetral que rodea los muros sur y este de la iglesia que ha eliminado la relación entre la cripta y la terraza que la rodea.

\section{CONCLUSIONES}

Los trabajos en curso sobre la Basílica da Ascensión y Os Fornos se iniciaron el año 2007 en el contexto de una intervención arquitectónica. Considerando el interés de los resultados otros proyectos han permitido articular un programa de investigación complejo.

Hemos recuperado una secuencia constructiva de larga duración, con raíces en la Edad del Hierro, que se transforma en la tardoantigüedad, la Edad Media y la Edad Moderna de la mano de la difusión de la leyenda de Santa Mariña y su fijación en el paisaje local.

No hemos podido fechar la sauna primitiva. Sólo una intervención más ambiciosa en el entorno del conjunto o en el suelo del sector 3 podría aportar más luz, aunque no tenemos seguridad al respecto, pero sí creemos que hay datos suficientes para considerar que el edificio primitivo era una sauna de la Edad del Hierro.

Por otra parte, la datación obtenida para la segunda fase nos obliga a retrasar nuestra hipótesis inicial, ya que fecha los muros de la antecámara en el siglo VI d.C. Esta fecha se relaciona con la fijación de la leyenda de Mariña y la cristianización del paisaje de Augas Santas. Esta constatación abre nuevas hipótesis de trabajo y nos obliga a ampliar la zona de estudio a otros edificios del entorno que presentan aparejos similares. Es esta la fase de trabajo en la que nos encontramos ahora.

\section{AGRADECIMIENTOS}

Este estudio ha sido financiado por diferentes proyectos:

"Levantamiento volumétrico y lectura de alzados del conjunto formado por la Basílica da Ascensión y O Forno da Santa (Allariz, Ourense)" (CD 102A 2007/646-0). Promovido por la Xunta de Galicia, directora: Rebeca Blanco-Rotea. Proyecto de investigación "Arqueoloxía e Relixión: da Idade do Ferro á Idade Media" (INCITE 2010 - Xunta de Galicia, Ref. 10PXI210112PR), IP: Marco V. García Quintela.

Programa de investigación en tecnologías para la valoración y conservación del patrimonio cultural. Programa Consolider-Ingenio 2010", convocatoria 2007 (Ref. CSD2007-00058). IP: Prof. Felipe Criado Boado.

EMCHAHE: Early Medieval Churches: History,

${ }^{19}$ Se encontraron en 1962 se conservan en el museo parroquial y están siendo objeto de estudio. 
Archaeology and Heritage, financiado por una ayuda europea Marie Curie Career Integration Grant (Grant agreement PCIG12-GA-2012-334068), IP: José Carlos Sánchez Pardo.

Queremos expresar nuestro agradecimiento a Marco V. García Quintela y Felipe Criado-Boado por su apoyo a la línea de trabajo aquí presentada. Han contribuido a su desarrollo Patricia Mañana Borrazás, Anxo Rodríguez Paz, Alberto Rodríguez Costas, Cruz Ferro, César González-García y José Carlos Sánchez-Pardo.

\section{BIBLIOGRAFÍA}

BANDE Rodríguez, E. \& ARMADA BANDE, O. 2002. Evolución do conxunto histórico-artístico de Santa Mariña de Augas Santas. Ourense, Diputación Provincial de Ourense.

BARANDEla Rivero, I. \& Lorenzo Rodríguez, J. M. 2011. El culto a Santa Mariña en el norte de la Península Ibérica y sus conexiones con la Europa Atlántica. Porta da Aira, 13: 117-143.

BlanCO-RoteA, R. \& GARCÍA RodRÍGUEZ, S. 2008. Lectura de alzados e estudo documental do mosteiro de San Pedro de Rocas, Esgos (Ourense). In: P. VAREla CAMPos (Coord.) 2008, Actuacións Arqueolóxicas. Ano 2006, Santiago de Compostela, Xunta de Galicia: 96-7.

Blanco-RoteA, R.; MAÑANA-BorrazÁS, P.; MATOFresÁn, C. \& Rodríguez-CostAs; A. 2009a. La basílica de la Ascensión y Os Fornos (Allariz, Ourense). Revista Aquae Flaviae, 41: 467-478.

Blanco-Rotea, R.; Benavides García, R.; SANJURJO SÁNCHEZ, J. \& FERNÁNDEZ MOSQUERA, D. 2009b Evolución constructiva de Santa Eulalia de Bóveda (Lugo, Galicia). Revista Arqueología de la Arquitectura, 6: 149-198.

Brogiolo, G. P. 1988. Archeologia dell'edilizia storica. Como, Edizioni New Press.

Burgess R. W. 1993. The Chronicle of Hydatius and the Consularia Constantinopolitana. Two contemporary accounts of the final years of the Roman Empire. Oxford, English translation by Oxford, Clarendon Press.

CABAllero ZoredA, L. 1995. Método para el análisis estratigráfico de construcciones históricas o "lectura de paramentos". Informes de la Construcción, 453: 37-46.

CABAllero Zoreda, L 1996. El análisis estratigráfico de construcciones históricas. In: L. CABALLERO ZOREDA \& C. Escribano Velasco (Eds.) 1996, $\mathrm{Ar}$ queología de la Arquitectura. El método arqueológico aplicado al proceso de estudio y de intervención en edificios históricos, Salamanca, Europa Artes Gráficas: 55-74.

Calvo, F. 1913. Recuerdos de Augas Santas I y II. Boletín de la Comisión Provincial de Monumentos de Orense, 91 (VI): 322-389.

CAstiñEIRAs GonZÁlez, M. A. 1990. La reutilización de piezas romanas y medievales en Galicia. Brigantium, 6: 77-90.

Chamoso Lamas, M. 1955. Santa Marina de Augas Santas. Cuadernos de Estudios Gallegos X-20: 41-88.

CONDE-VAlvís FernándeZ, F. 1955. Las termas romanas de la "Cibdá" de Armeá en Santa María de Augas Santas. In: Actas del III Congreso Nacional de Arqueología (Galicia 1953), Zaragoza, Institución Fernando el Católico, CSIC: 436-466.
Conde-VAlvís FernándeZ, F. 1959. Dos villas romanas de la Cibdá de Armea, en Santa Mariña de Augas Santas. Revista de Guimarâes, 69: 472-500.

Fariña Busto, F. 2002. Santa Mariña de Augas Santas Guías do Patrimonio Cultural, 7. Santiago de Compostela, Fundación Caixa Galicia.

FeAthers, J.K.; Johnson, J. \& Kembel, S.R. 2008. Luminescence Dating of Monumental Stone Architecture at Chavín De Huántar, Perú. Journal of Archaeological Methods and Theory, 15: 266-296.

García Quintela, M. V. 2014a. Marina concubina, Marina virgen, Boand adúltera: fecundidad extra-marital y creación de paisajes. In: Ma TAUSIET, H. TROPÉ (eds.), Folclore y leyendas en la península ibérica. En torno a la obra de François Delpech, Madrid, CSIC: 57-80.

García Quintela, M. V. 2014b. Paisajes duales en la Galicia tradicional: estructura, génesis y transformación. Revista de Dialectología y Tradiciones Populares, LXIX (1): 29-52.

García Quintela, M. \& Santos Estévez, M. 2015. Iron Age Saunas of Northern Portugal: State of the Art and Research Perspectives. Oxford Journal of Archaeology, 34 (1): 67-95.

García Quintela, M. V. \& Seoane-Veiga, Y. 2011. La Larga Vida de dos rocas ourensanas. Archivo Español de Arqueología, 84: 241-264.

García Quintela, M. V. \& Seoane-Veiga, Y. 2013. Entre naturaleza y cultura: la arquitectura Ambigua en la Edad del Hierro del Noroeste de la Península Ibérica. Gallaecia, 32: 47-86

GARCíA Y Bellido, A. 1940. El castro de Coaña (Asturias) $\mathrm{y}$ algunas notas sobre el posible origen de esta cultura. Revista de Guimarães, 50 (3-4): 284-311.

García y Bellido, A. 1942. El castro de Pendía. Archivo Español de Arqueología, 15: 288-307.

GoEDICKE, C. 2011. Dating mortar by optically stimulated luminescence: A feasibility study. Geochronometria, 38: 42-49.

LORENZO FERNÁNDEZ, J. 1948. El monumento protohistórico de Augas Santas y los ritos funerarios en los Castros. Cuadernos de Estudios Gallegos, 3: 157-211.

MañanA-BorrazÁs, P.; Rodríguez Paz, A. \& BlanCORoteA, R. 2008. Una experiencia en la aplicación del Láser Escáner 3D a los procesos de documentación y análisis del Patrimonio Construido: su aplicación a Santa Eulalia de Bóveda (Lugo) y San Fiz de Solovio (Santiago de Compostela). Revista Arqueología de la Arquitectura, 5: 15-32.

Morales, A. de 1574. La Coronica General de España. Alcalá de Henares, Casa de Juan Iñiguez de Lequeríca.

Molina, Licenciado 1675 (1 $1^{\text {a }}$ Ed. 1550). Descripcion del Reyno de Galicia y de las cosas notables del. Madrid ( $1^{\mathrm{a}}$ ed. en Mondoñedo).

MuÑoz DE LA Cueva, J. 1719 [reimpresión facsímil 2005]. Breve compendio de la vida y martyrio de la Gloriosa Virgen y Martyr Sta. Marina de Galicia, cuyo sepulcro y santo cuerpo se venera en su Iglesia de Aguas Santas. A Coruña.

MuÑoz DE LA Cueva, J. 1726 [reimpresión facsímil 2008]. Noticias históricas de la Santa Iglesia Cathedral de Orense. A Coruña. 
NuÑEZ, M. 1978. Historia da Arquitectura Galega. Arquitectura prerrománica. Santiago de Compostela, COAG.

PARENTI, R. 1995. Historia, importancia y aplicaciones del método de lectura de paramentos. Informes de la Construcción, 435: 19-29.

Pereira Marión, C. 1991. As cerámicas medievais de Santa María de Augas Santas (Allariz, Ourense). In: Arqueoloxía Informes 2, Santiago de Compostela, Xunta de Galicia: 347-350.

Pesce, G. L. A. \& BaLl, R. J. 2012. Dating of Old Lime Based Mixtures with the "Pure Lime Lumps". D MichalsKa NaWrocka (Ed.), Technique, Radiometric Dating, InTech, Available from: http:// www.intechopen.com/books/radiometric-dating/ dating-of-old-lime-basedmixtures-with-the-purelime-lumps-technique: 21-38.

Quirós Castillo, J. A.; Marzaioli, F. \& Lubritto, C. 2011. Dating mortars: three medieval Spanish architectures. Arqueología de la Arquitectura, 8: 1324.

Rivas FernánDeZ, J. C. 1971. Algunas consideraciones sobre el prerrománico gallego y sus arcos de herradura geminados. Boletín Auriense, I: 61-125.

SANJURJo SÁNCHEZ, J. 2012. Dating Bricks and Mortars of Ancient and Historical Buildings. In: S.M. Rivera, A.L. Pena, (Eds), Brick and Mortar Research, New York, Novapublishers: 171-193.

THACKER, A. 2002. Loca sanctorum: the significance of place in the study of the saints. In: A. THACKER \& R. SHARPE (eds.). Local saints and local churches in the early medieval West, Oxford, Oxford University Press: $1-43$. 